\title{
An Overview of Current Capabilities and Research Activities in the Airspace Operations Laboratory at NASA Ames Research Center
}

\author{
Thomas Prevot ${ }^{1}$, Nancy Smith ${ }^{2}$, Everett Palmer ${ }^{3}$ \\ NASA Ames Research Center, Moffett Field, CA 94035 \\ and
}

Todd Callantine ${ }^{4}$, Paul Lee ${ }^{5}$, Joey Mercer $^{6}$, Jeff Homola $^{6}$, Lynne Martin $^{5}$, Connie Brasil ${ }^{6}$, Christopher Cabrall $^{6}$ San Jose State University/NASA Ames Research Center, Moffett Field, CA 94035

The Airspace Operations Laboratory at NASA Ames conducts research to provide a better understanding of roles, responsibilities, and requirements for human operators and automation in future air traffic management (ATM) systems. The research encompasses developing, evaluating, and integrating operational concepts and technologies for near-, mid-, and far-term air traffic operations. Current research threads include efficient arrival operations, function allocation in separation assurance and efficient airspace and trajectory management. The AOL has developed powerful air traffic simulation capabilities, most notably the Multi Aircraft Control System (MACS) that is used for many air traffic control simulations at NASA and its partners in government, academia and industry. Several additional NASA technologies have been integrated with the AOL's primary simulation capabilities where appropriate. Using this environment, large and small-scale system-level evaluations can be conducted to help make near-term improvements and transition NASA technologies to the FAA, such as the technologies developed under NASA's Air Traffic Management Demonstration-1 (ATD-1). The AOL's rapid prototyping and flexible simulation capabilities have proven a highly effective environment to progress the initiation of trajectory-based operations and support the mid-term implementation of NextGen. Fundamental questions about accuracy requirements have been investigated as well as realworld problems on how to improve operations in some of the most complex airspaces in the US. This includes using advanced trajectory-based operations and prototype tools for coordinating arrivals to converging runways at Newark airport and coordinating departures and arrivals in the San Francisco and the New York metro areas. Looking beyond NextGen, the AOL has started exploring hybrid human/automation control strategies as well as highly autonomous operations in the air traffic control domain. Initial results indicate improved capacity, low operator workload, good situation awareness and acceptability for controllers teaming with autonomous air traffic systems. While much research and development needs to be conducted to make such concepts a reality, these approaches have the potential to truly transform the airspace system towards increased mobility, safe and efficient growth in global operations and enabling many of the new vehicles and operations that are expected over the next decades. This paper describes how the AOL currently contributes to the ongoing air transportation transformation.

\footnotetext{
${ }^{1}$ Research General Engineer, Human Systems Integration Division, NASA ARC, MS 262-4, AIAA senior member

${ }^{2}$ Research Psychologist, Human Systems Integration Division, NASA ARC, MS 262-4, AIAA member.

${ }^{3}$ Human Factors Engineer, Human Systems Integration Division, NASA ARC, MS 262-4.

${ }^{4}$ Senior Research Engineer, Human Systems Integration Division, SJSU/NASA ARC, MS 262-4, AIAA member.

5 Senior Research Psychologist, Human Systems Integration Division, SJSU/NASA ARC, MS 262-4, AIAA member.

${ }^{6}$ Research Associate, Human Systems Integration Division, SJSU/NASA ARC, MS 262-4, AIAA member.
} 


\section{Nomenclature}

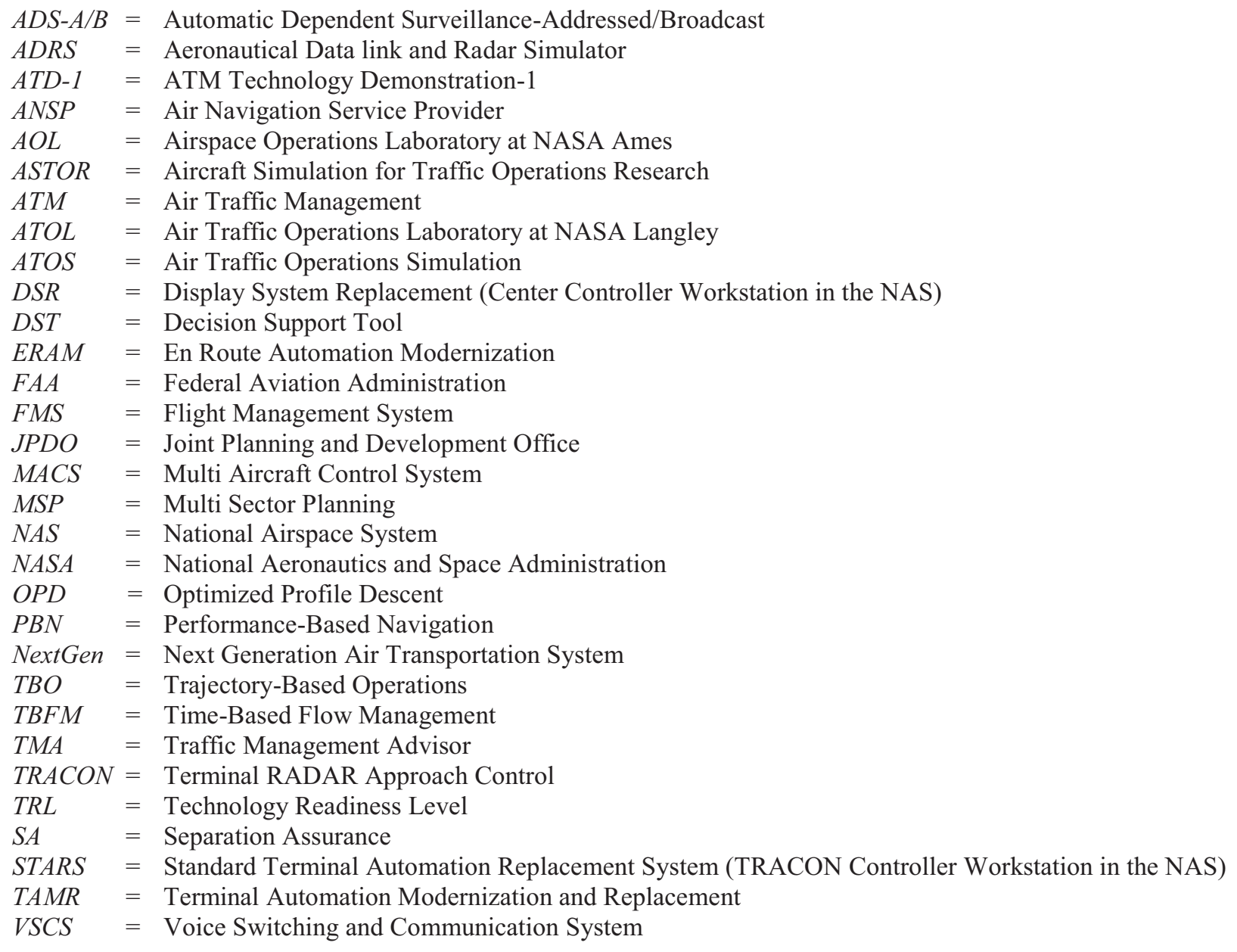

\section{Introduction}

GOR more than 15 years the Airspace Operations Laboratory (AOL) at NASA Ames has conducted research to - provide a better understanding of roles, responsibilities, and requirements for human operators and automation in future air traffic management (ATM) systems. The research encompasses developing, evaluating, and integrating operational concepts and technologies for near-, mid-, and far-term air traffic operations. At the AIAA Modeling and Simulation Technologies conferences in 2006 and 2010 we presented overviews of the AOL's capabilities and research with a focus on capabilities and features that were new at that time ${ }^{1,2}{ }^{2}$. Following the theme of the preceding papers, this paper starts with a brief introduction of the main challenges and activities, and then describes the current laboratory capabilities with a focus on the most recent improvements. The second part of the paper provides an overview of the current research activities.

NASA's aeronautics research is aimed at solving the challenges that still exist in our nation's air transportation system: air traffic congestion, safety and environmental impacts ${ }^{3}$. NASA's Airspace Systems Program performs foundational research to enable the development of revolutionary improvements to, and modernization of, the National Airspace System (NAS). The AOL conducts research in support of both, the gradual modernization of the NAS through a thorough simulation evaluation of near-term improvements, as well as the development of revolutionary concepts. Therefore, the AOL engages not only in the integration and evaluation of high TechnologyReadiness-Level (TRL) components in a high-fidelity lab environment, but also in the rapid prototyping of highly advanced potential future capabilities. Over the past few years the AOL, together with other major NASA ATM laboratories, participated in several research threads that required additional ground automation and flight-deck capabilities developed at NASA Ames' Aviation System Division and at NASA Langley's Air Traffic Operations 
Laboratory (ATOL). A number of development activities in recent years were related to integration of these technologies. These efforts led to highly capable simulation platforms across several NASA laboratories.

In addition to integrating other technologies, the AOL also added many new capabilities to its simulation platform, the Multi Aircraft Control System MACS ${ }^{4}$. These include more accurate emulations of the latest Terminal Radar Approach Control (TRACON) and en route controller workstation, many advanced scenario editing functions, increased support for trajectory based operations from take-off to touchdown, new controller tool prototypes, additional options for configuring system uncertainties, and increased support for autonomous operations. MACS has been distributed to many partners in government, industry and academia. Several groups have modified it further to meet their needs, for example to support research on Unmanned Aerial Systems or single pilot operations. MACS is being further improved and geared towards new vehicles and operations, keeping pace with current and future research needs. Except where noted all displays and functions described in the following section are part of MACS and its communication process ADRS. An overview over some of the current capabilities in the AOL is given next.

\section{Airspace Operations Laboratory Capabilities}

\section{A. Laboratory Layout}

The AOL is located on the second floor of building N-262 at NASA Ames Research Center. The offices of the AOL's research and development team are located directly next to the lab space.

The laboratory extends across two areas that are in close proximity to each other. The " 280 " area is depicted in Figure 1 and the H211 area is depicted in Figure 2.

There are eight workstations in room 280A and H209 that can be used by the experimenters to start and monitor the simulations. 60 workstations are for the use of simulation participants, including air traffic controllers, air traffic managers, area supervisors, multi aircraft pilots and single aircraft pilots. The lab is laid out for maximum flexibility in conducting the research activities. All positions can be

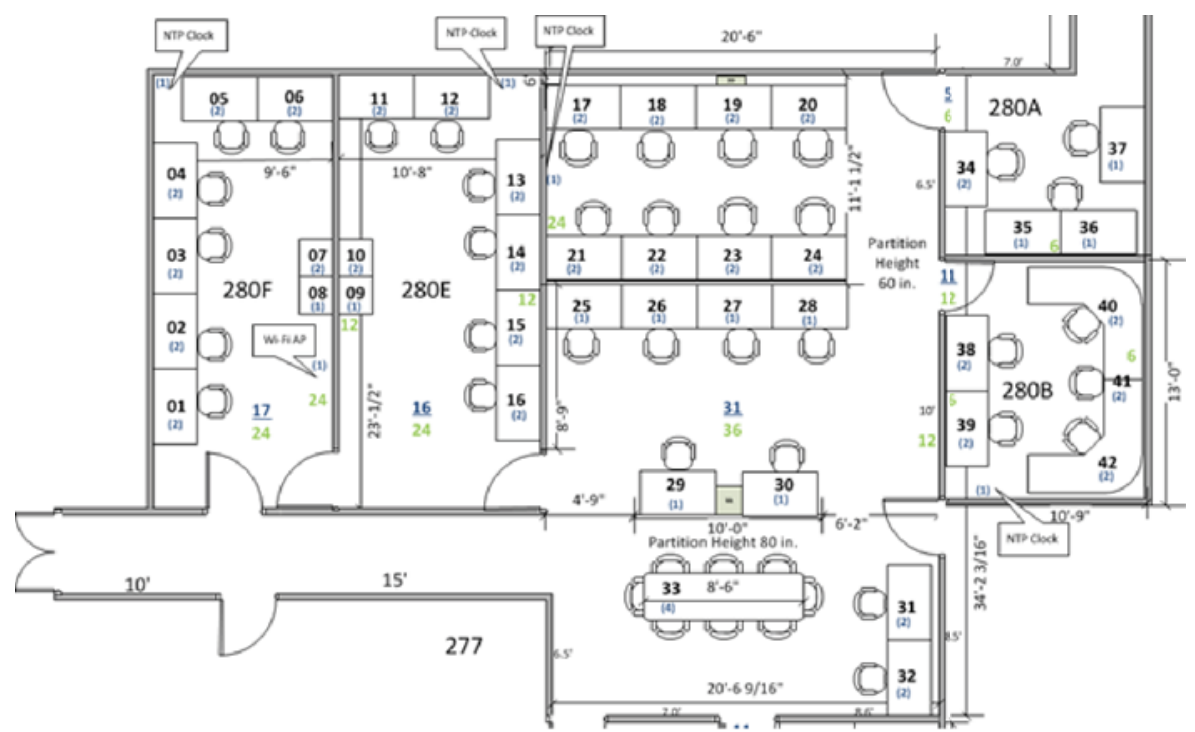

Figure 1: AOL 280 area. combined in one large simulation or many small "worlds" can be run in parallel, operating as independent simulations that do not interfere with each other.
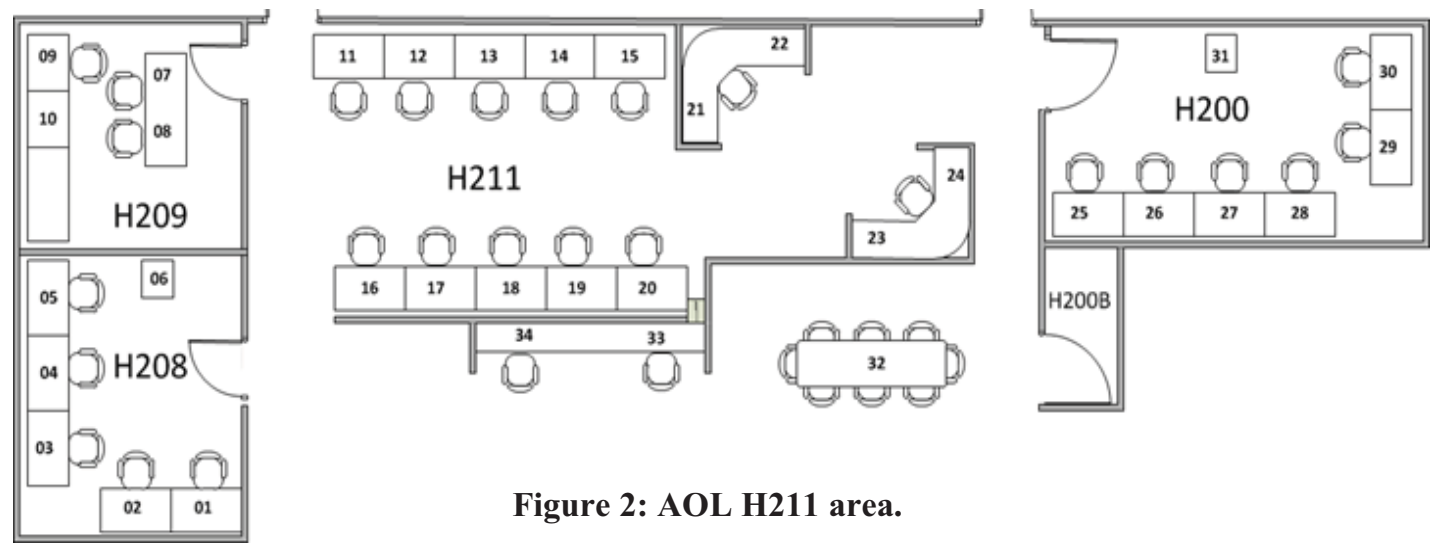

Figure 2: AOL H211 area. 


\section{B. Air Traffic Control}

There are a total of 23 air traffic control sector positions in four air traffic control rooms (rooms 280E, 280F, H208 and H209). Each room is equipped with a supervisor station, overhead projector and either five or six sector positions. Figures 3 and 4 show the 280E air traffic control room configured for TRACON operations during a simulation of ATD-1.

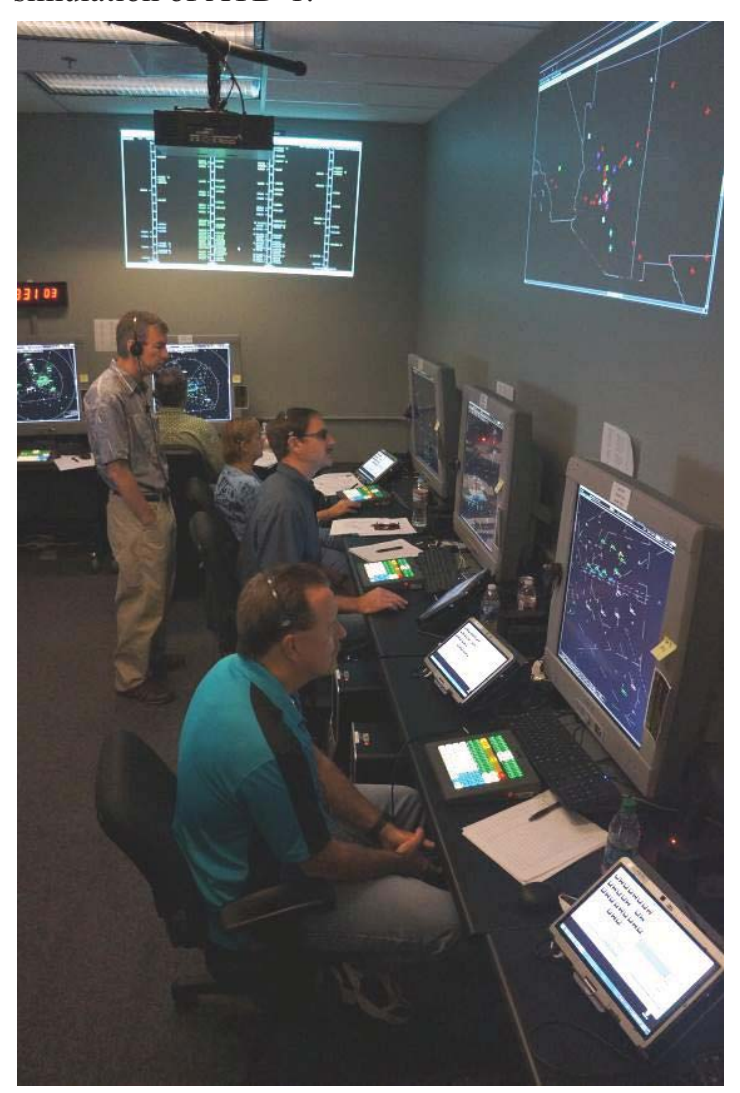

Figure 3: Air Traffic Control room (280E) in TRACON configuration.

Unlike the TRACON workstations, the en route controller workstations are available in two different look and feel settings. One configuration emulates the Display System Replacement (DSR) that was in operational use in the NAS for the past two decades. New since 2013, MACS can also emulate the look and feel of the En Route Automation Modernization (ERAM) ${ }^{7}$ radar workstations that are replacing the DSR in the NAS. Figure 5 shows an en route sector controller position with the ERAM keyboard and the MACS emulation of the radar display. The ERAM emulation in the AOL currently has several of the basic functions and menus, such as the macros, flight plan readouts, the continuous range readouts, the meter lists, and supports ERAM-specific processing of most of the command line inputs. Additional radar controller (R-side) views and functions, as well as various displays that are located on the ERAM side panel and/or radar associate (D-side) position, are currently under development in MACS.

In addition to the sector controller positions shown here, MACS ATC stations can also be configured for traffic management positions and oceanic controller stations. MACS also includes the capability to 'link' ATC workstations, such that they can be used as R- and D-Side pairs that link display information between each other, such as data tag positions and contents, route displays and J-Rings.
The pictures show the wall projections of a MACS-based Traffic Situation Display (TSD) on the right wall, and a Traffic Management Advisor (TMA) ${ }^{5}$ timeline display on the back ll. The sector controller positions are equipped with MACSand Replacement (TAMR) program ${ }^{6}$. Controllers use the STARS keyboards for data entry and conduct air/ground and und/ground communications via a tablet, which hosts . prove 4 also shows the supervisor station on the left that provides additional access to TMA and traffic data and is used

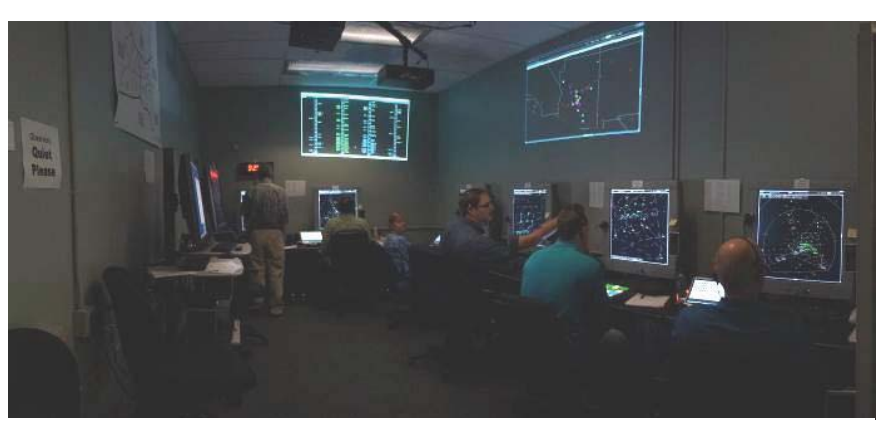

Figure 4: Different view of the Air Traffic Control room during simulation in the AOL.

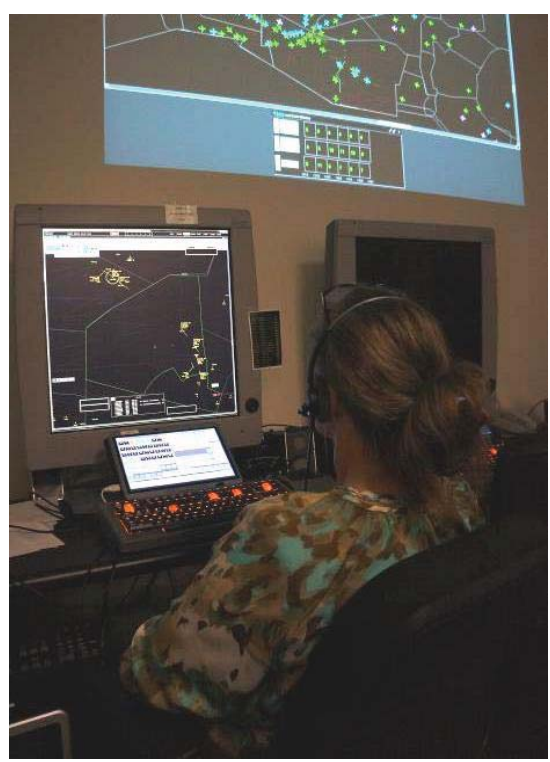

Figure 5: En route controller workstation with ERAM emulation. 


\section{Multi-Aircraft Flight Decks}

The multi-aircraft flight decks are used to control the majority of aircraft in a simulation. Generally one such pilot station is used to control the aircraft that are on a given controllers frequency. When the controller instructs the pilot to contact the next sector on a different frequency, the pilot selects this new frequency, which transfers the aircraft to the multiaircraft station for that next sector. Figure 6 shows typical multi-aircraft workstations in the AOL's

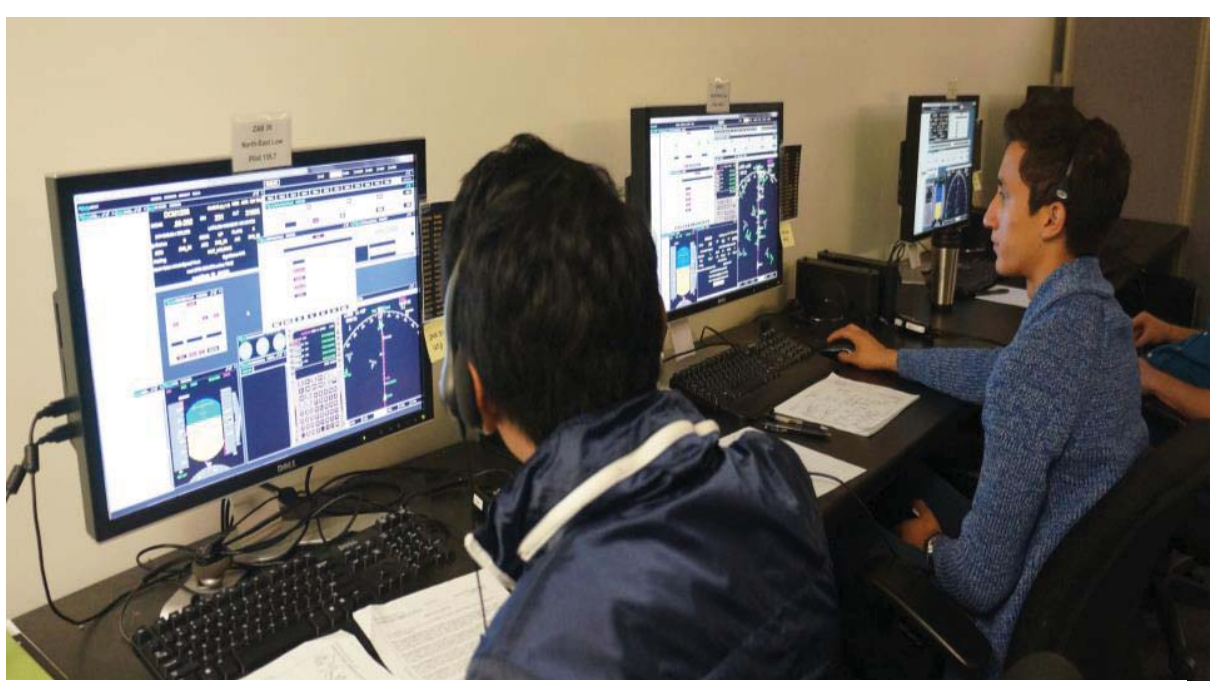

Figure 6: Multi aircraft pilot stations in the AOL. H211 area.

Figure 7 highlights some of the details encapsulated in the pilot stations. Aircraft flight IDs are shown in different lists. One list shows all flight IDs that are controlled by a given station. Prompts remind pilots to take

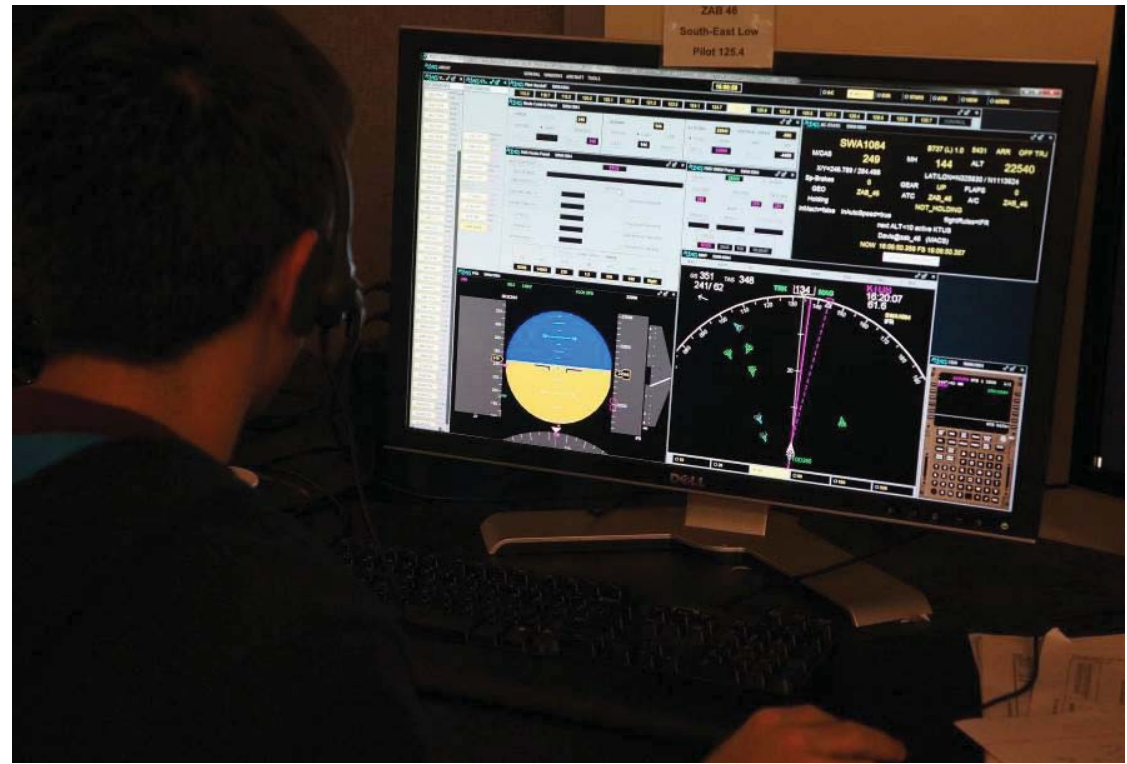

Figure 7: Close up view of MACS pilot station. specific actions when necessary. Some of the recent work in MACS has added additional filtering options for these reminders, enabling experimenters to customize them based on different criteria, such as route of flight, altitude, flight rules, equipage and more.

When the flight ID is selected, the displays show the view from that particular aircraft and the pilot can use the input devices to control that aircraft's flight management computer and flight control system.

MACS supports using different aero models. The AOL and most other labs primarily use an enhanced point/mass model that is designed for groundfocused air traffic management research purposes. Other laboratories prefer a four-degree-of-freedom (4DOF) model that adds more aerodynamic characteristics required for flight deck-centered research. Each model supports the performance characteristics of all major aircraft types. Scale factors can be used on a per aircraft basis to simulate variations in climb/descent ratios of individual aircraft.

\section{Single-Aircraft Flight Decks: NASA Langley's ASTOR System}

Several research projects require advanced flight deck operations and equipment, and/or validation of procedures and phraseology that cannot be easily conducted with MACS' multi- or single-aircraft flight decks. Therefore, NASA Langley's Aircraft Simulation for Traffic Operations Research (ASTOR) ${ }^{8}$ has been fully integrated with the simulation capabilities in the AOL (see Figure 8). This enables the AOL, as well as other labs at NASA Ames, to include several ASTOR desktop flight simulators in ATM simulation. It also provides NASA Langley's ATOL with the ability to include MACS capabilities and operator workstations into their simulations. 


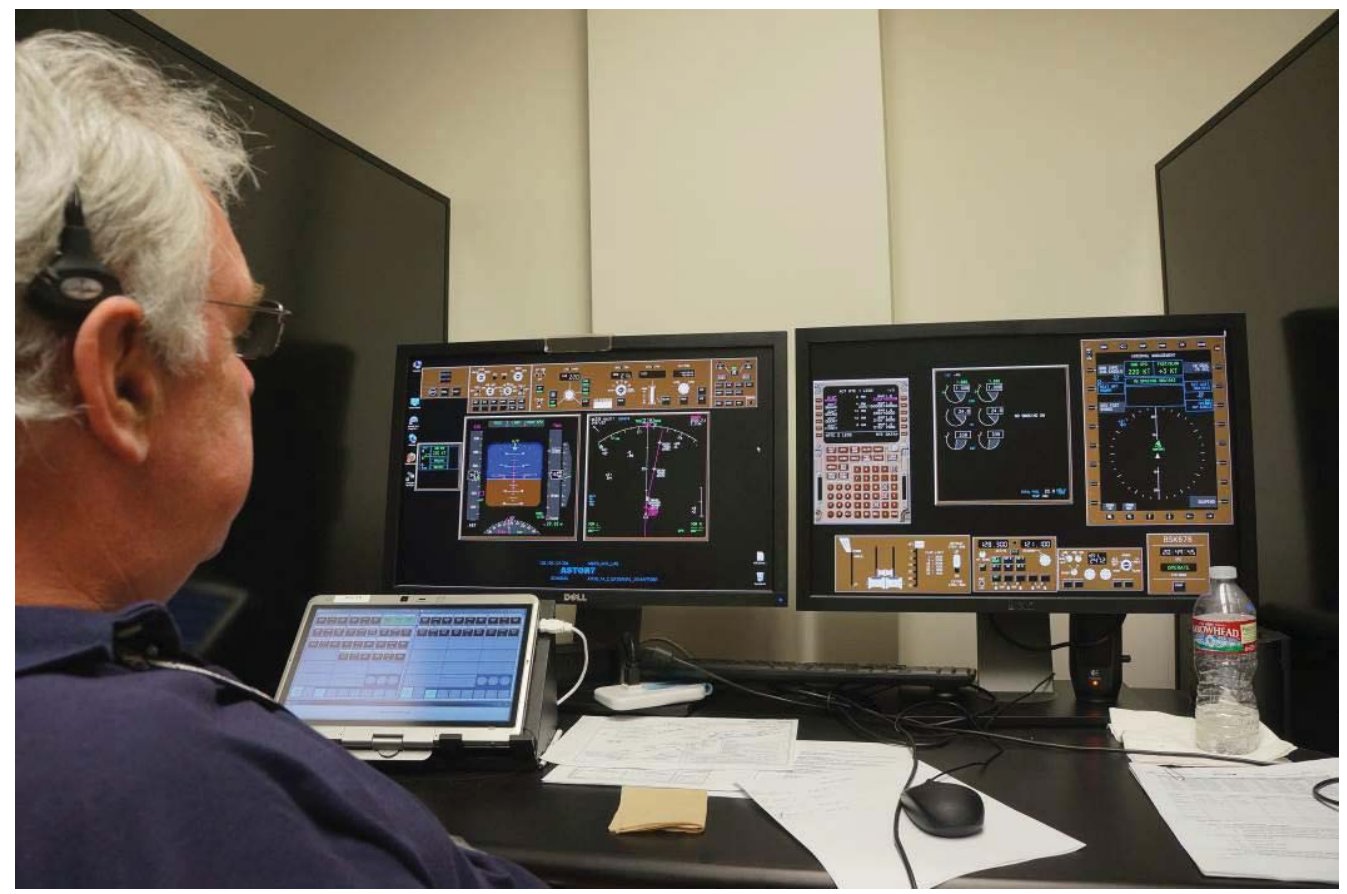

Figure 8: One of eight ASTOR flight simulator stations in the AOL.

\section{E. Air Traffic Management}

MACS has provided considerable air traffic management simulation capabilities for several years now ${ }^{9,10}$. These capabilities were designed to simulate future trajectory-based operations and did not attempt to precisely replicate existing functions in the field. In support of research on NASA's ATD-1 project, the flight deck and air traffic control simulation capabilities have been fully integrated with TMA, a fielded metering system originally developed at NASA Ames. For this integration, the Aeronautical Radar and Data link Simulator (ADRS) (the simulation communication network) has been extended to provide data connections to TMA that provide and consume the same data formats used by the FAA's fielded host, ERAM and STARS systems. This enables NASA and its partners to evaluate its near-term ATD-1 TMA functional enhancements for terminal metering in a realistic environment.

This connectivity also enables NASA to include TMA into other projects focused on trajectory-based operations, as well as additional TMA features and functions. For example, Figure 9 shows an arrival management station that

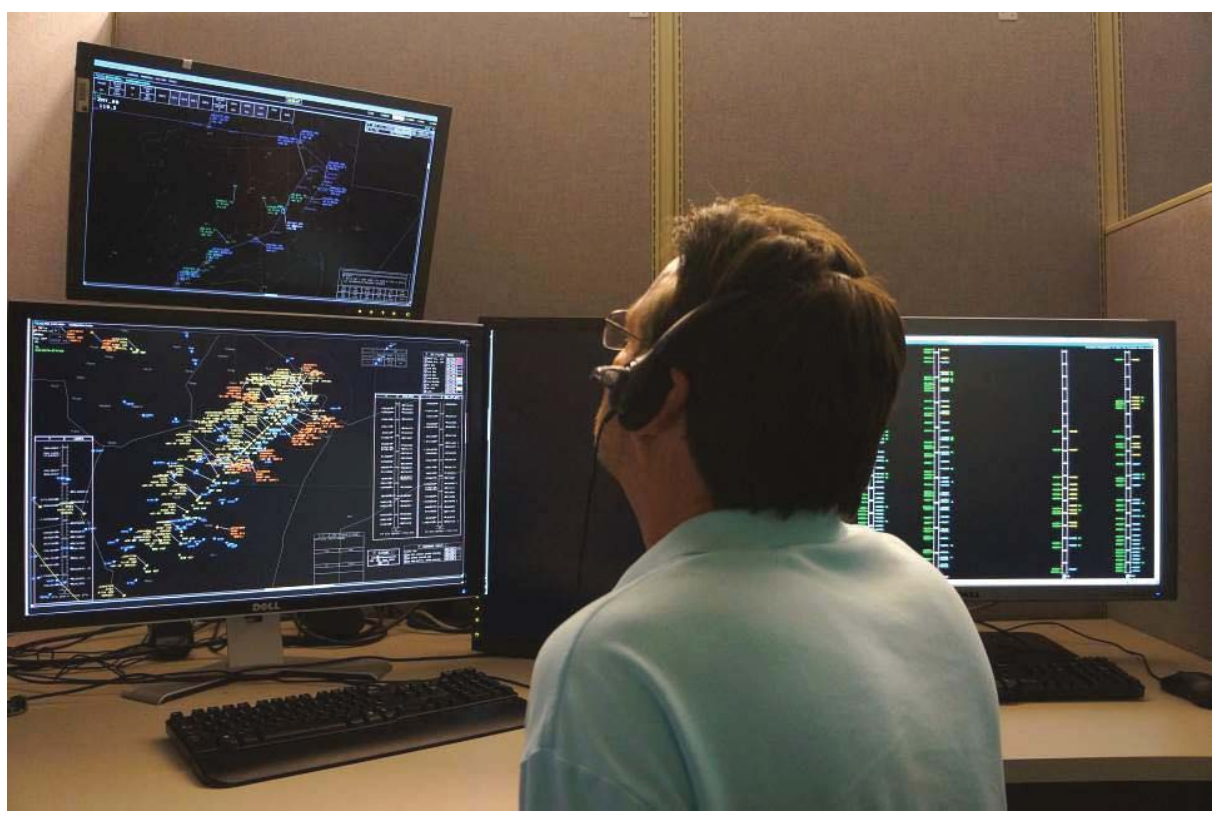

Figure 9: Integrated arrival management station with MACS (left) and TMA (right) displays.

6

American Institute of Aeronautics and Astronautics 
combines MACS prototype functions with TMA. This station was used for a recent simulation investigating new ways to coordinate the intersecting runways at Newark airport ${ }^{11}$. This research will be described in the second half of this paper.

\section{F. Airspace and Complexity Management}

MACS incorporates extensive capabilities to investigate airspace and complexity management research questions. These capabilities include powerful tools for complexity assessment, airspace sector combining and decombining, dynamic sector redesign and dynamic reconfiguration. These capabilities have been used in various research projects for NASA and the $\mathrm{FAA}^{12}$. Figure 10 shows a configuration that was used for an evaluation of the Operational Airspace Sectorization Integrated System (OASIS) advisory tool in the AOL ${ }^{13}$

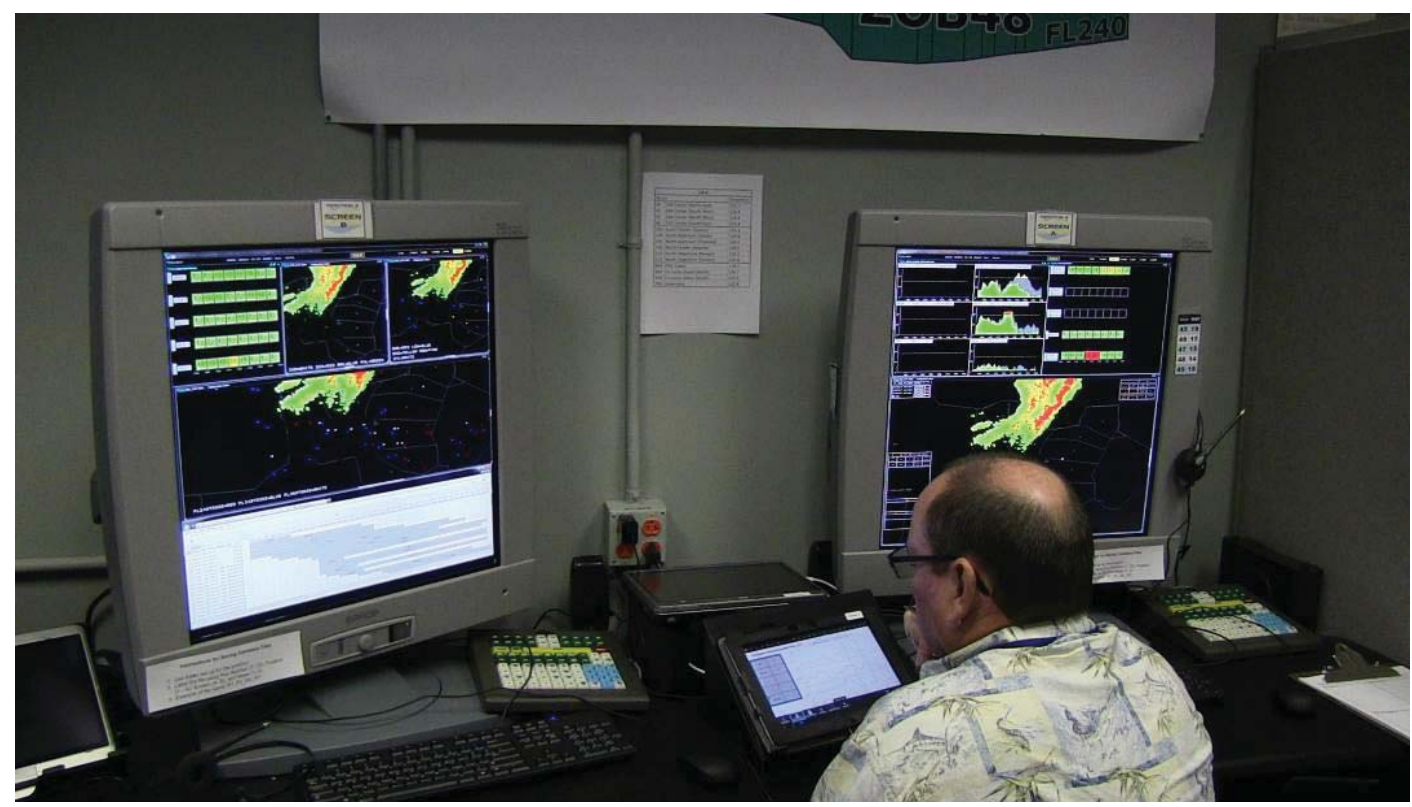

Figure 10: Evaluation of the OASIS advisory tool in AOL with two MACS displays for airspace and complexity assessment and OASIS tablet (center).

\section{G. Manual, Hybrid and Autonomous Air Traffic Operations}

In support of more advanced future concepts, MACS incorporates the capability to conduct air traffic operations at different levels of human/automation function allocation, ranging from manual, to hybrid operations, to fully autonomous air traffic operations. This capability is achieved by utilizing NASA technologies for scheduling and spacing as well as conflict detection and resolution, such as the Autoresolver and TSAFE functions ${ }^{14,15}$ for resolving mid- and short-term conflicts by the air traffic control system, and integrating them with digital data communications between the ground-based and the airborne systems. These functions can be utilized manually by air traffic controllers or autonomously by the system or in a hybrid mode based on tolerances that can be selected by the experimenter or operator. Using these functions, studies on evaluating the impact of uncertainties on autonomous

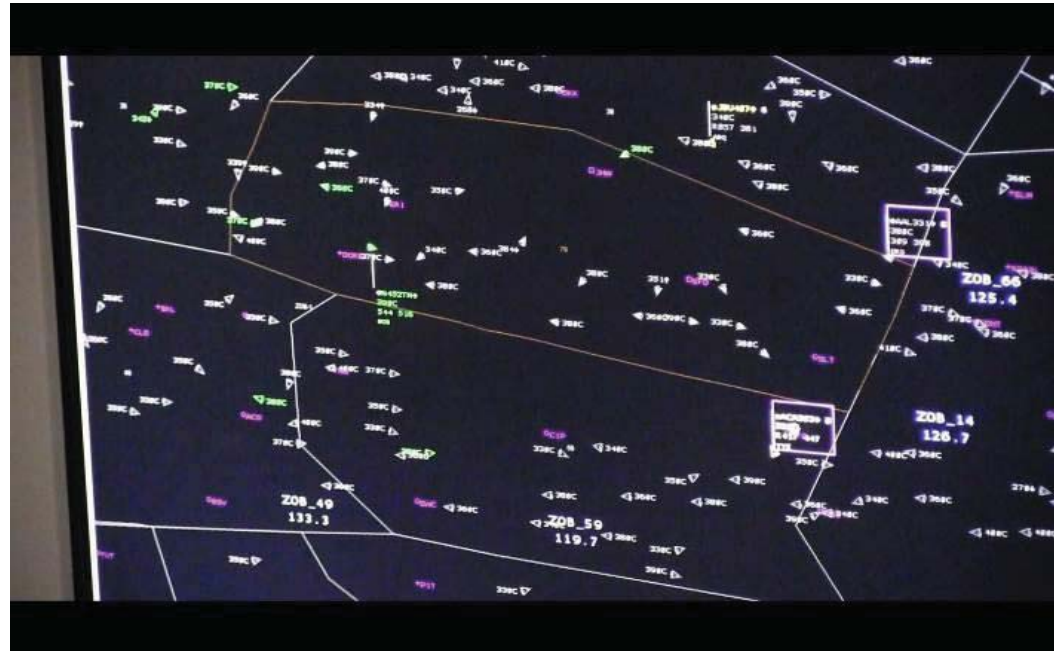

Figure 11: Human/autonomy teaming during simulation on automated separation assurance. 
system functions and on human/autonomy teaming can be conducted. Figure 11 shows an air traffic controller display designed for managing largely autonomous air traffic operations. Green aircraft manage their own separation; white aircraft are managed by the ground automation. The two aircraft with rectangles around them have been taken over manually by the controller to prevent an undesirable conflict resolution from automatically being issued by the system. Figure 12 shows controllers monitoring the simulated air traffic system conducting largely autonomous operations.

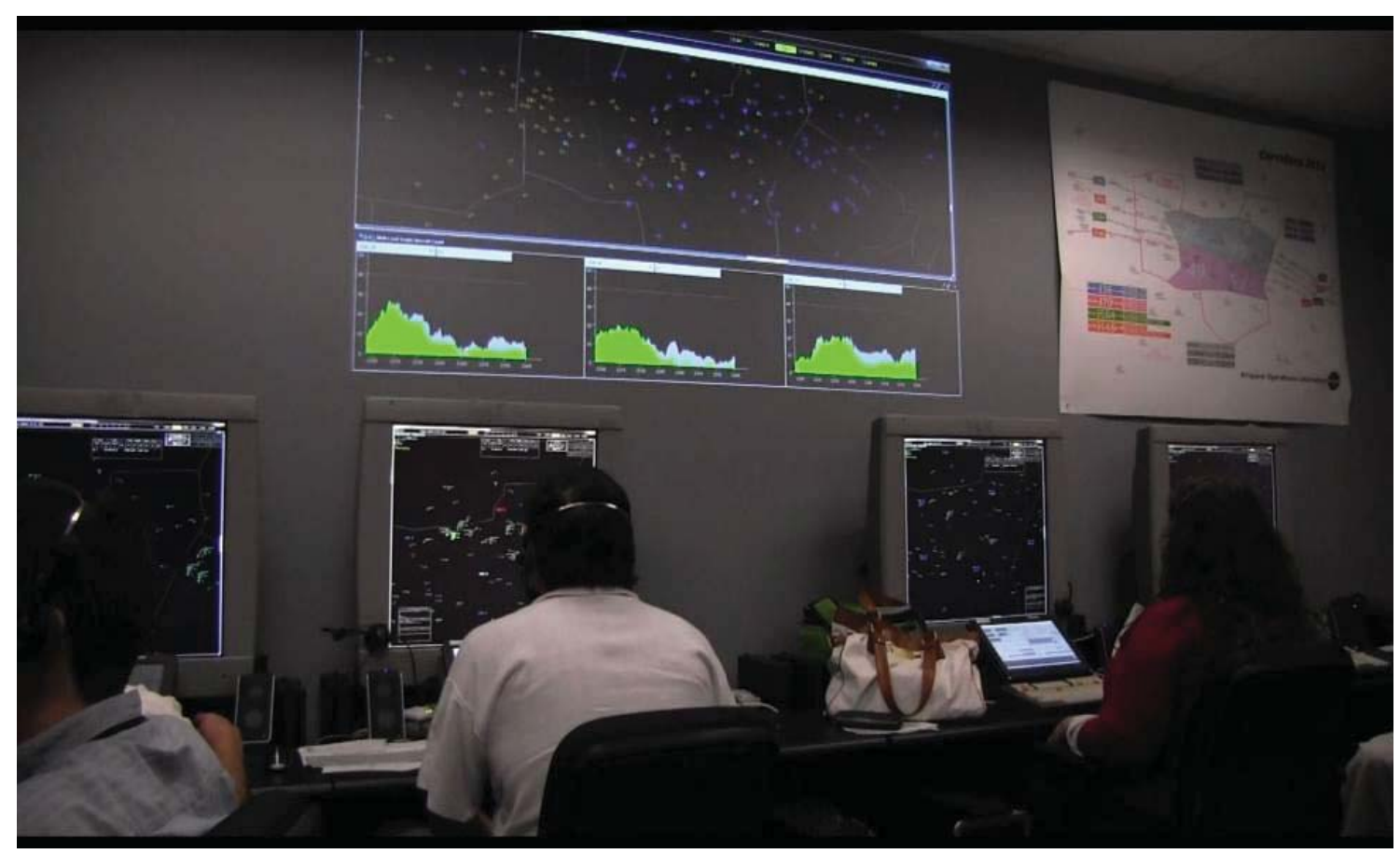

Figure 12: Air traffic controllers monitoring largely autonomous operations.

\section{Research Activities in the AOL}

Research activities in the AOL are focused on system level evaluations and human/automation integration and teaming aspects for advanced operations enabled by new NASA ATM technologies. The activities align with three major categories and target epochs: Near-Term Improvements, Initiating Trajectory-Based Operations and Increased System Autonomy.

\section{A.Near-Term Improvements}

When targeting near-term improvements to the NAS, typically the highest level of fidelity is required to properly reflect the actual environment, in which new technologies or concepts are to be deployed. By accurately emulating fielded systems and integrating new technologies into full scale simulations, the AOL can quickly provide early estimates of system-level effects and support design iterations at early stages. This can largely improve the probability of a successful introduction of new concepts and technologies.

\section{System-Level Evaluation of ATD-1 Operations}

NASA initiated ATD-1 to demonstrate increased, more consistent use of Performance-Based Navigation (PBN), demonstrate an Automatic Dependent Surveillance Sytem - Broadcast-In (ADS-B-In) spacing application, and accelerate the transfer of NASA scheduling and spacing technologies for operational deployment. ATD-1 is a multiyear collaborative effort between researchers at NASA Ames and Langley Research Centers, the FAA, and industry partners to integrate, mature, and operationally demonstrate NASA-developed technologies that have attained a sufficient level of maturity to merit in-depth, system-level research in relevant environments ${ }^{16}$. 
ATD-1 integrates scheduling automation, Controller-Managed Spacing (CMS) tools, and ADS-B-enabled Flight Deck-based Interval Management (FIM) avionics (see Figure 13). The scheduling system is the Traffic Management Advisor for Terminal Metering (TMA-TM) developed at NASA Ames. TMA-TM represents a significant advancement from the currently deployed TMA automation system originally developed as part of NASA's CenterTRACON Automation System (CTAS) ${ }^{5}$. To construct arrival schedules tailored for high-throughput Continuous Descent Operations (CDOs), TMA-TM computes trajectory predictions using Area Navigation (RNAV) routes in the TRACON, rather than simple transit-time estimates, to generate schedules that are de-conflicted at each TRACON merge point.

FIM capabilities are implemented using the Airborne Spacing for Terminal Arrival Routes (ASTAR) algorithm developed at NASA Langley. ASTAR uses ADS-B data to provide speed commands to flight crews, enabling aircraft to precisely achieve an assigned spacing interval behind a target aircraft at a specified 'achieve-by' point. FIM operations are expected to reduce TRACON controller workload and contribute

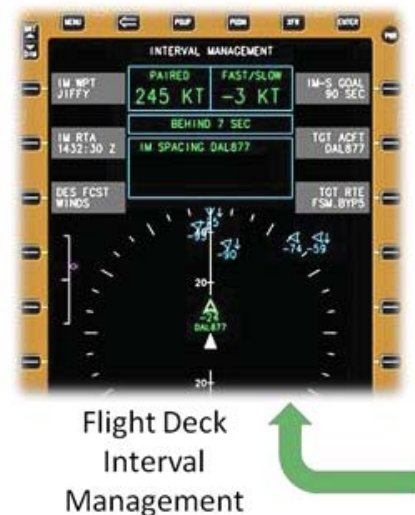

(FIM)

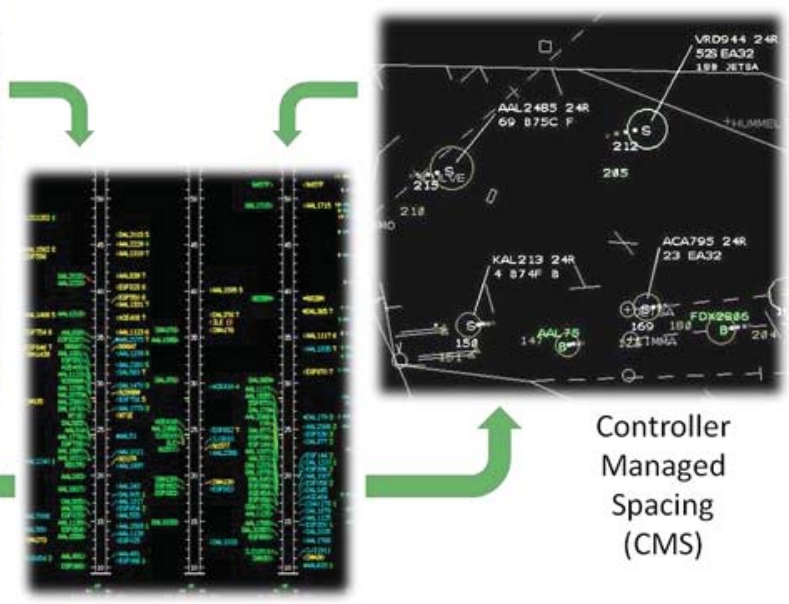

Traffic Management Advisor with Terminal Metering (TMA-TM)

\section{Figure 13: ATD-1 Technologies.}

additional inter-arrival precision for increasing the proportion of uninterrupted CDOs achievable with high throughput.

Although ATD-1 has a distinct TRACON focus, operations begin when TMA-TM acquires each aircraft while it is still in cruise. TMA-TM assigns aircraft a runway, and computes estimated times-of-arrival (ETAs) at the meter fix, runway, and at intervening metering points (e.g., TRACON fixes where RNAV routes merge). It then uses the ETAs, together with required spacing information, to assign scheduled times-of-arrival (STAs) at each scheduling point. When an aircraft reaches a 'freeze horizon,' specified at a site-specific distance (e.g., $200 \mathrm{nmi}$ ) from the TRACON, TMA-TM locks in the aircraft's STA to provide a stable control target. En-route controllers then begin working to 'precondition' the aircraft using vectoring or other techniques as necessary to reduce the delay and make sure the aircraft is within the speed-control margin. Following preconditioning, en-route controllers reestablish aircraft on RNAV routes (e.g., by clearing aircraft direct to the meter fix), and clear aircraft for CDOs. These procedures enable flight crews to use their onboard Flight Management Systems (FMSs) to fly efficient profiles from cruise until landing (or until a radar vector is required to turn the aircraft to join the approach procedure).

Once a FIM-equipped aircraft has been preconditioned and established on an RNAV OPD, the controller may issue it a FIM clearance. After the crew enters the required parameters into the onboard system (e.g., an Electronic Flight Bag (EFB)) and the target aircraft enters ADS-B range, the FIM avionics begin displaying speed commands to achieve the required spacing at the achieve-by point. For non-FIM aircraft, TRACON controllers use the CMS tools to issue speeds to ensure proper inter-arrival spacing while maintaining CDOs. Under nominal conditions, aircraft should cross the meter fix within their speed-control margin for correcting residual schedule errors and adjusting for disturbances due to winds or other factors inside the TRACON. Because controllers retain separation responsibility, they may find it necessary to interrupt CDOs or suspend FIM operations if they deem small adjustments from the nominal speed profile insufficient to maintain safe separation. All of the procedures and clearance phraseology for these operations are documented in the ATD-1 Concept of Operations ${ }^{17}$.

After a systematic evaluation of component technologies in highly coordinated studies, a large scale system-level evaluation of ATD-1 operations was conducted in three phases in 2013 and 2014. These simulations, entitled Controller Managed Spacing for ATD-1/\#5 (CA5) were three large-scale, distributed air and ground simulations intended to quantify expected efficiency and capacity gains under realistic operational conditions when using the ATD-1 ground-based and airborne technologies. In the first simulation ('CA-5.1'), controllers worked simulated traffic using current-day workstations and control techniques. The second simulation ('CA-5.2') introduced the TMA-TM and CMS tools, while the third simulation ('CA-5.3') added the airborne technologies. All simulations 


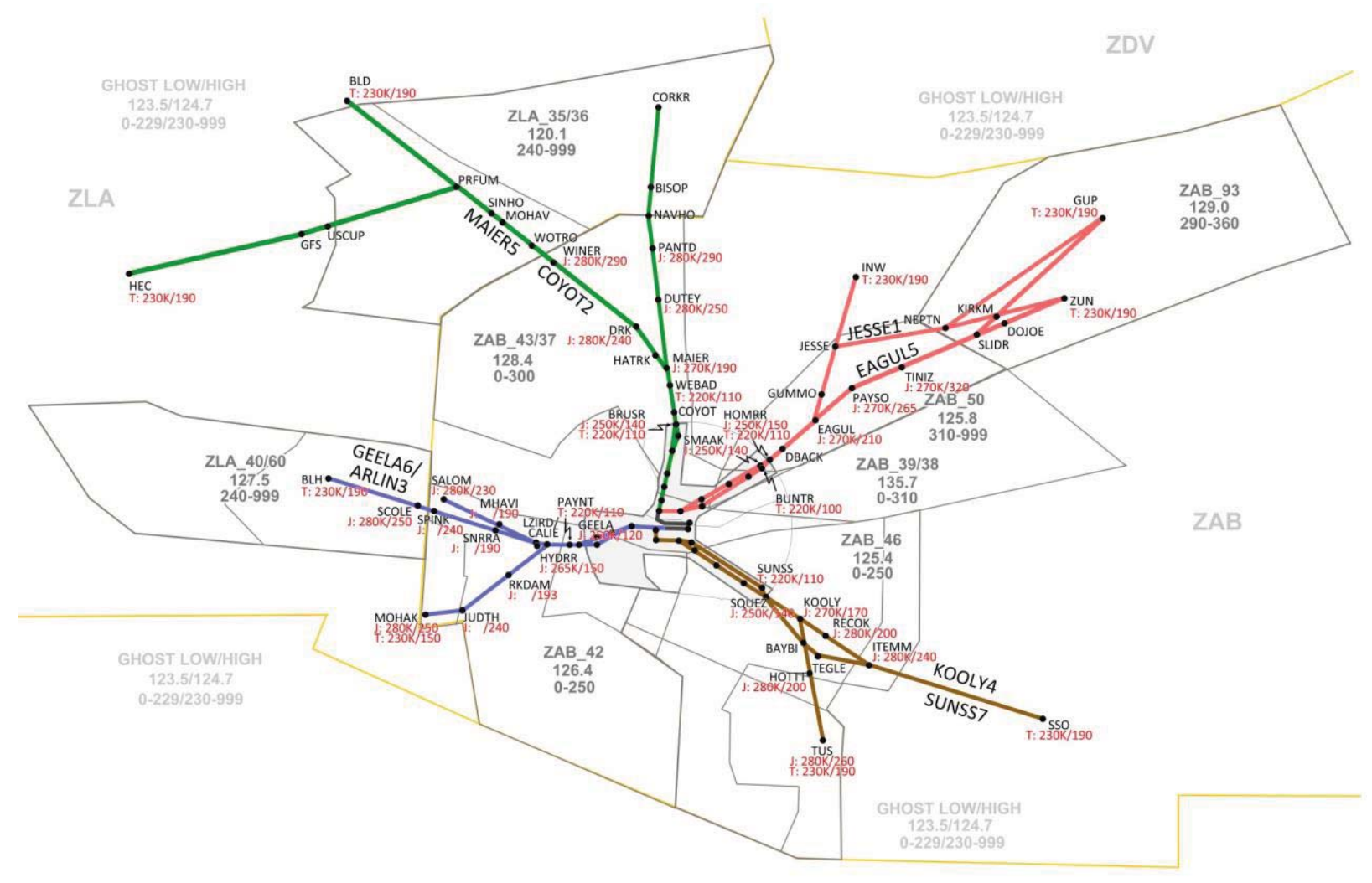

Figure 14: Airspace for System-Level Evaluation of ATD-1 Technologies.

used east- and west-flow traffic scenarios derived from recorded Albuquerque Center (ZAB) and Phoenix TRACON (P50) traffic that included peak-period arrivals into Phoenix Sky Harbor International Airport (PHX) in different sets of historical ZAB truth and forecast winds. Former ZAB and P50 traffic managers operated the Traffic Management Advisor to create an efficient arrival schedule. Eight former ZAB controllers used MACS ERAM workstation emulations to meter traffic into P50. Former P50 controllers then used MACS STARS workstation emulations with CMS tools to manage the aircraft along efficient descent paths according to the schedule. Eight airline pilots flew ASTOR desktop flight simulators. Five confederate controllers and eighteen general aviation and corporate pilots also participated. Controllers managed approximately seventy-five arrivals per hour-long scenario, along with approximately two hundred departures and over-flights. A map of the airspace used during the CA5 simulations is shown in Figure 14.

The CA-5.1 and CA-5.2 system-level simulations suggest that ATD-1 ground-tool operations are viable in a fullscale operational environment with controllers who have received only a limited amount of training on the concept and CMS tools. While their unfamiliarity appears to have contributed to slightly lower acceptability than would be expected from experienced controllers, performance generally improved under operations with ATD-1 ground-tools. CMS tool ratings again were highly consistent with those observed in prior research, with controllers finding the slot markers most usable and useful. ${ }^{18}$

CA-5.3 afforded examination of all aspects of ATD-1 operations in a realistically complex traffic environment. The TMA-TM used runway allocation and an adaptation updated to include all aircraft types which, particularly for PHX west-flow operations, typically led to several aircraft scheduled on cross-over routes. Digital and questionnaire data were collected for all trials, and are currently being analyzed and correlated with experimenter observations. Data are expected to provide detailed information about FIM clearances, FIM in relation to en-route flow conditioning, FIM aircraft behavior relative to the slot markers, FIM operations in crossover situations, FIM speed commands, FIM spacing performance, TMA-TM schedule performance, CMS tool performance, ATD-1 Minimum Operation Performance Standards (MOPS) values, and also pilot and controller training, workload, and acceptability. More information is available in ${ }^{19}$.

The ATD-1 technologies are being transferred to the FAA, with the ground-based technologies representing core components of the FAA's Terminal Sequencing and Spacing (TSS). In order to support the technology transition and the FAA's decision making, the Arrival Metering Precision Study (AMPS), described next, was conducted in the AOL in May 2014. 


\section{Arrival Metering Precision Study (AMPS)}

In May 2014 the Arrival Metering Precisions Study (AMPS) was conducted to provide supporting data for the introduction of ATD-1 technologies. The effectiveness of ATD-1 ground-based technologies and TSS will be impacted by the accuracy at which aircraft are delivered by Center controllers to the TRACON boundary. Arrival metering in the en-route airspace is performed using Time-Based Flow Management (TBFM) equipment, the fielded version of TMA. When activated, this equipment relays each aircraft's STA and current estimated delay value to the air traffic controller's ERAM workstation. The delay countdown timers (DCTs) on the controller workstations can be configured with different levels of precision. The currently available options are displaying the delay rounded to 10's of seconds, rounded to the next minute, or truncated to minutes (see Figure 15).

The first research objective for AMPS was to assess the delivery accuracy at the TRACON boundary for the different DCT resolutions. The second question was aimed at the use of the controller entered speed intent to update the ETA. Prior research ${ }^{22}$ has shown that not knowing the speed intent of the aircraft has a significant impact on the ETA and DCT accuracy, and can contribute to reduced efficiency and increased controller workload. The FAA's Ground-based Interval Management-Speed (GIM-S) function will utilize speed intent in addition to providing speed advisories. While AMPS did not use speed advisories, the speed intent was forwarded to the TBFM prototype to be reflected in the ETA and DCT (see Figure 16).

The delay magnitude was varied within each traffic scenario and created by restricting the arrival rate over the corner post within TMA. This led to a non-uniform delay distribution with the desired properties, simulating a TSS environment without actually populating the entire airspace. DCT resolution and $4^{\text {th }}$ line speed condition were varied within subjects between runs. It is expected that the delay resolution has a significant impact on the delivery accuracy while the use of the $4^{\text {th }}$ line speed may have an impact on controller workload and flight efficiency. Figure 17 shows a visualization of the study's design.

Data for AMPS was collected during a simulation of arrival traffic into the Northwest corner of Atlanta airspace in May 2014 using realistic traffic samples. The primary participants were four air traffic controllers that had retired less than a year before the study. The data analysis is currently underway and results are expected to be presented later this year. Airspace and scenarios re-used much of the environment created for studying the impact of trajectory prediction uncertainty on controller performance and acceptability of automation, described next.

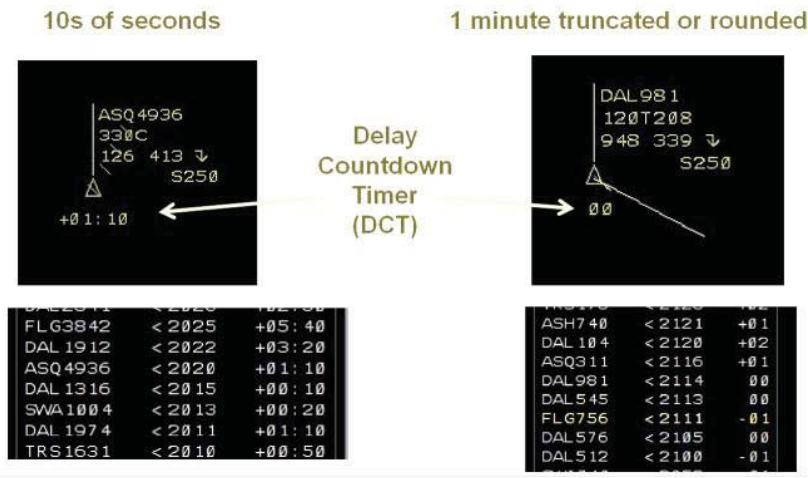

Figure 15: Options to format the delay countdown timer

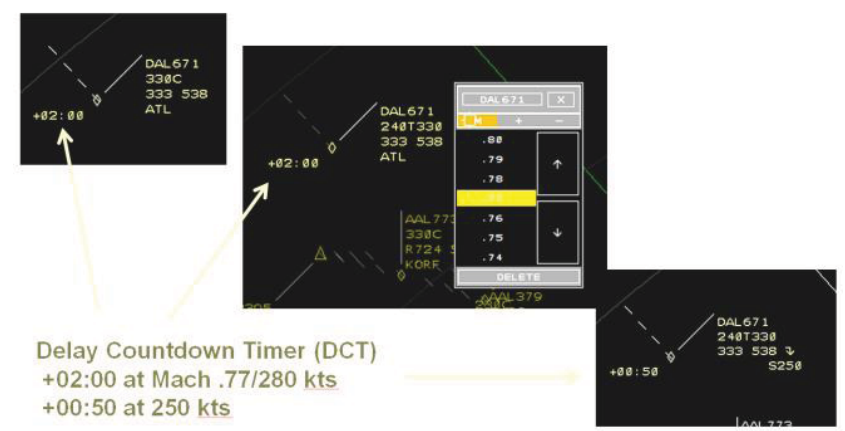

Figure 16: Use of controller entered speed to update the DCT.

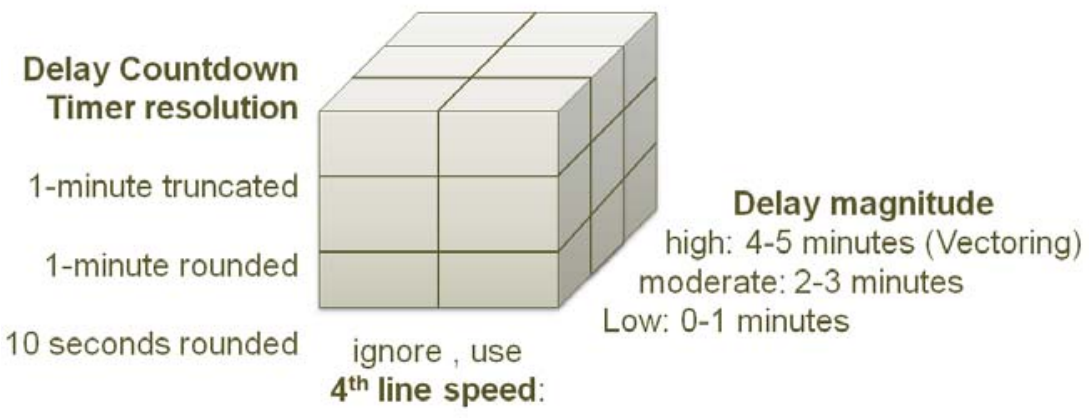

Figure 17: Factors varied for AMPS. 


\section{B.Initiating Trajectory-Based Operations (TBO)}

The US and Europe have made four-dimensional (4D) -TBO a primary cornerstone of their air traffic initiatives NextGen $^{20}$ and SESAR ${ }^{21}$. The key element of the conceptualized TBO is that the airline and the ATM negotiate the trajectory that will be followed by an aircraft. This trajectory should satisfy many of the airline preferences and include additional constraints, such as controlled times of arrival to improve predictability for the air traffic controllers. Initiating TBO is considered a critical step in moving towards NextGen and beyond. Several research activities in the AOL help evaluate the effectiveness of particular aspects of TBO. One study investigated the impact of trajectory prediction uncertainty on controller performance and acceptability of automation on a more fundamental level. Also, to explore the effectiveness of NextGen technologies and TBO within the most challenging environment, substantial research activities in the AOL are using the New York area airspace to identify potential operational improvements. The third TBO-related research activity in the AOL investigates the integration of arrival and departure trajectory planning and scheduling. All three activities are described below.

\section{Impact of Trajectory Prediction Uncertainty on Controller Performance and Acceptability of Automation}

Predictability is a major concern in TBO. Without accurate intent information, a trajectory predictor has to guess at the future route, altitude and speed of aircraft. Inaccurate forecasts and models of the environment, aircraft performance and flight technical errors cause additional uncertainties that will negatively impact the quality of the trajectory predictions. Given the many potential error sources in trajectory-based systems, a fundamental question has to be answered when deploying new trajectory-based technologies and moving towards TBO: "How accurate must a trajectory prediction be to support successful NextGen TBO concepts?"

The overall approach to addressing the problem was to first conduct fast-time simulations to identify and quantify the primary and most significant error sources, and then to run a human-in-the-loop (HITL) experiment to determine the controller workload and performance under variations of the dominant error sources.

The HITL presented air traffic controllers with challenging, but manageable, time-based metering problems, formulated specific performance targets for the controllers and then varied the errors and uncertainties to see when the performance would start degrading. We had postulated that if the automation performance degraded, the controllers would have to issue more clearances to correct for the bad "automation advice". Eventually, they would run out of resources and could not issue any more clearances. We expected to see performance targets not being met and that we would have found the point at which the automation was not accurate enough anymore.

The following performance targets were chosen:

a) Encounter No Loss of Separation (LOS) events

b) Deliver aircraft to the meter fix as accurately as possible, at least within 25 seconds of their STA

The following errors had been identified to be realistic error sources and have the biggest impact on the automation performance:

- Wind forecast errors

- Aircraft performance errors

- Flight technical errors

Figure 18 shows the error conditions tested in the study. They included a no error condition, realistic errors (e.g. $10 \mathrm{kts}$ wind error, $5 \%$ error in predicted descent performance) as well as largely exaggerated error conditions (e.g. $40 \mathrm{kts}$ wind error, $25 \%$ descent performance).

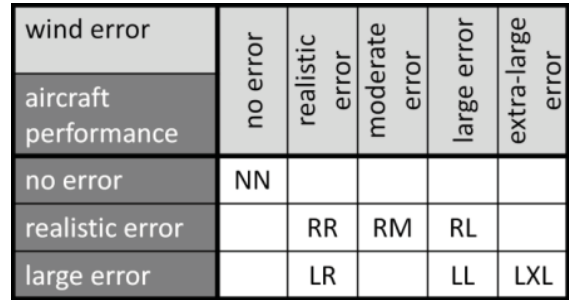

Figure 18: Tested combinations of wind forecast error and aircraft performance error.

Other factors that play a role in metering situations are controller technique and task difficulty. In order to gather a more comprehensive cross section of metering situations we decided to employ at least two different controller teams with potentially different techniques and to run the error conditions under varying task difficulties. More details about the experimental design and detailed results are presented in ${ }^{22}$.

The most significant finding from the study is depicted in Figure 19. For this analysis, when aircraft crossed the meter-fix, aircraft were classified into one of three groups: on time, early, and late. An aircraft was considered to arrive at the meter-fix on time if it arrived within 25 seconds of its STA. Aircraft arriving more than 25 seconds early relative to their STA were considered 'early', and those arriving more than 25 seconds late relative to their STA were considered 'late'. The formula used in this analysis was simply STA - Actual Time of Arrival (ATA), with positive values indicating early arrivals, and negative values indicating late arrivals. Overall performance was high; 578 of 598 aircraft (97\%) were delivered on time. In comparisons by error condition and traffic scenario, schedule conformance at the meter-fix was always at a $94 \%$ success rate or higher. Additionally, the raw STA-ATA 
values were tested for statistical significance across error condition and traffic scenario. Significant differences in data were not found in either comparison, indicating that the controllers achieved similarly high performance regardless of error condition or traffic scenario.

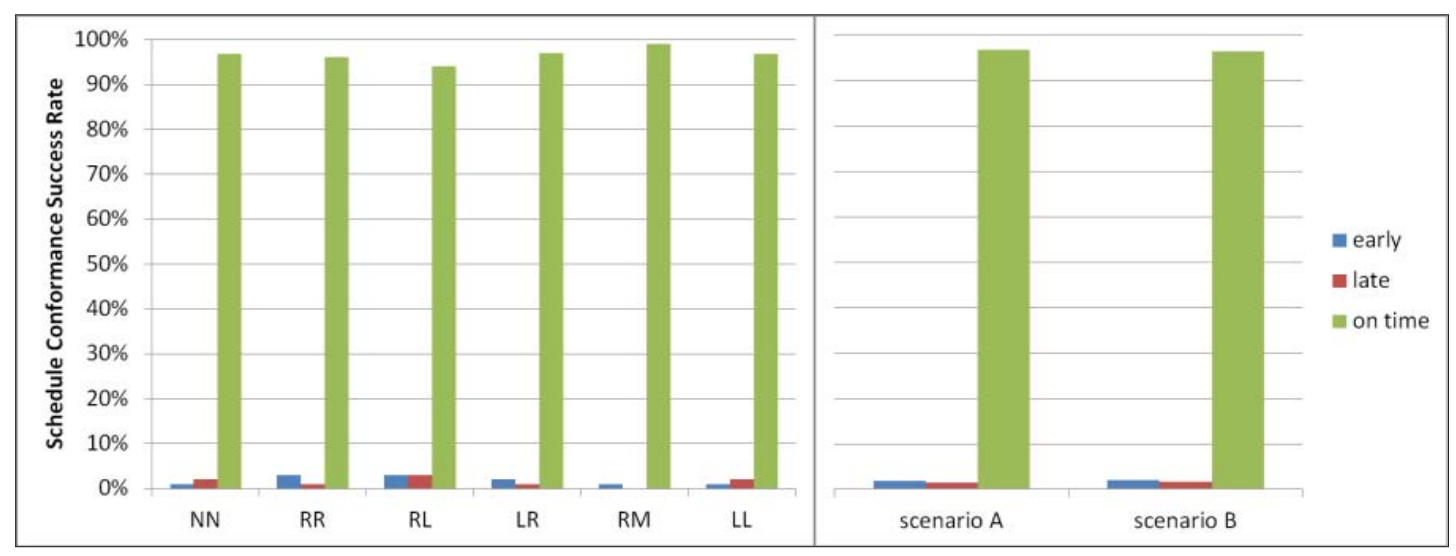

Figure 19: Percentage of aircraft delivered to the meter-fix either early, late, or on time, when compared across error conditions and traffic scenarios.

The results suggest that even in the largest trajectory prediction error conditions, controllers were able to learn how to compensate for the errors and adapt their interaction with the tools to deliver arrival aircraft on time and not exceed workload limits. In fact, the error conditions exhibited minimal impact on performance; rather, it was other factors, such as traffic scenario and tool availability, that had measurable impact on system performance. It is believed that the size of the errors managed by the controllers in this manual condition may prove difficult for a more automated system built to issue corrective updates automatically. This suggests the opportunity to enhance research on more far-term concepts and to incorporate corrective learning; much like the controllers did naturally in the simulation. In the presence of these errors, it is also likely that the transition from a controller-in-the-loop paradigm to a more autonomous system may be problematic without significant investigation and improvement to the learning abilities and calibration of the automation and the human/automation teaming concept.

\section{New York Operational Improvements}

The New York area airspace is notoriously complex and demanding, and is responsible for a large portion of the delays and congestion in the United States. A new research effort was initiated to examine the chronic problems associated with New York, and to develop integrated NextGen concepts that leveraged existing NASA and other NextGen technologies to reduce delays, increase throughput, and/or improve trajectory efficiencies in this region.

An initial HITL simulation in the AOL addressing the New York airspace explored the feasibility of a NextGen TBO solution to address airspace and airport capacity limitations in and around the New York Metroplex ${ }^{11}$. A concept, tools, and operational procedures for improving flight efficiency and runway throughput for EWR arrivals were developed to create a precise, dependent-runway schedule between two intersecting runways. A week-long study, conducted in August 2013, explored the feasibility of a new Optimal Profile Descent (OPD) arrival into the airspace as well as a novel application of the TMA-TM arrival scheduling tool to coordinate high volume arrival traffic to intersecting runways. In the simulation, four en route sector controllers and four TRACON controllers managed traffic inbound to EWR's primary runway, EWR22L, and its intersecting overflow runway, EWR11. TMA-TM was used to generate independent arrival schedules for each runway, while a traffic management coordinator participant adjusted the arrival schedule so that each EWR11 followed a EWR22L aircraft. CMS tools were also provided to assist the TRACON controllers in managing the arrivals descending on OPDs. 


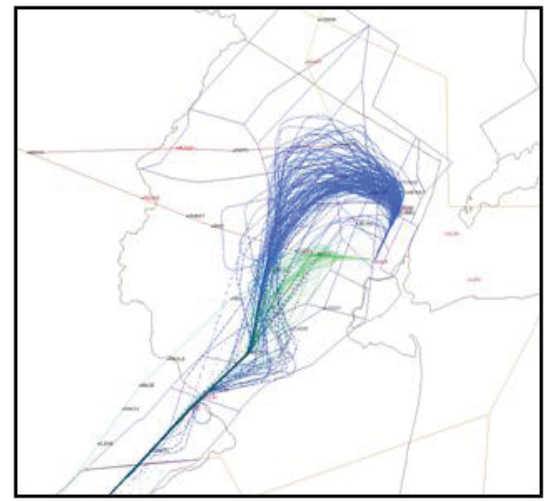

Actual Traffic

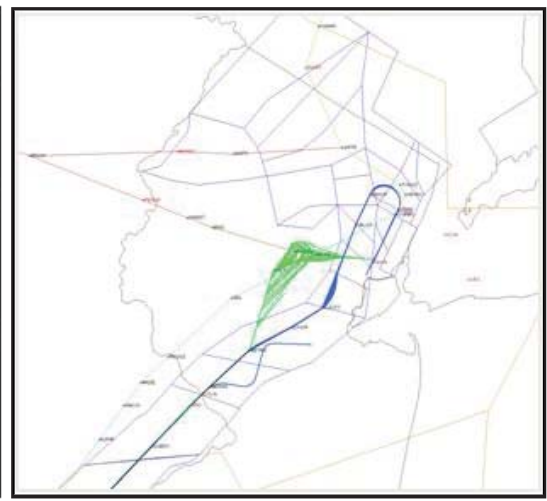

Baseline

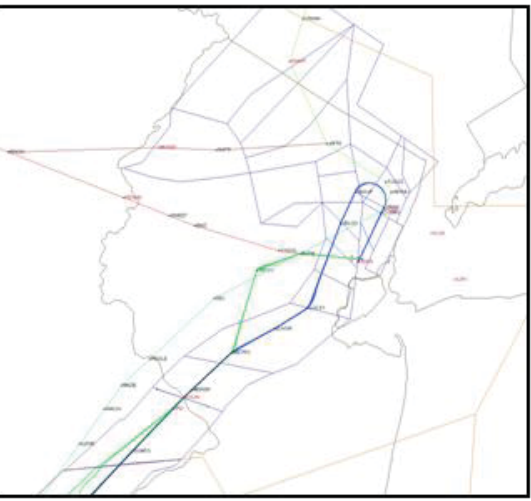

Futures

Figure 20: Trajectories from 2011/06/27 operational data (left), Baseline condition (middle) and Futures condition (right).

The study compared the throughput and safety of an experimental condition labelled Futures using the TMA-TM tools with dependent-runway scheduling, with a Baseline condition that did not. Figure 20 shows the lateral trajectories of the arrivals on OPDs in the Baseline and Futures conditions ( 5 hours of Baseline and Futures condition runs, with 190 and 198 simulation trajectories, respectively), compared to 24 continuous hours of actual operational data for arrivals from ZDC for EWR22L or EWR11 on a clear weather day (June 27, 2011, 316 aircraft trajectories). The figure illustrates that the OPD RNAV trajectories used in the study resulted in fewer lateral path deviations than the trajectories from the operational data.

The results suggested that the efficient RNAV descent procedures were compatible with converging-runway operations using the modified TMA-TM and the controller tools. Further, the combined use of the tools with the new OPDs produced a peak arrival rate of 67 aircraft per hour using instrument flight rules (IFR), exceeding the current maximum arrival rate at EWR of 52 per hour under visual flight rules (VFR). In the Futures condition, the controllers were able to deliver arrival aircraft precisely on OPDs at a high throughput rate for both EWR22L and EWR11 runways with less vectoring, fewer lateral path deviations, and a lower workload. More importantly, a coordinated schedule across the two intersecting runways at a high-throughput rate was successfully managed with minimal coordination using the TMA-TM tools. A coordinated schedule allowed the controllers to deliver their aircraft to the slot markers with the assurance that they would result in conflict-free delivery at the converging runways. The schedule and the slot markers were created taking winds in the account, and therefore the controllers could deliver the aircraft safely even during high wind conditions. In the Baseline condition, the controller needed to make last minute path adjustments on the EWR11 arrivals in order to pair them with the leading EWR22L arrivals, resulting in more lateral path deviations.

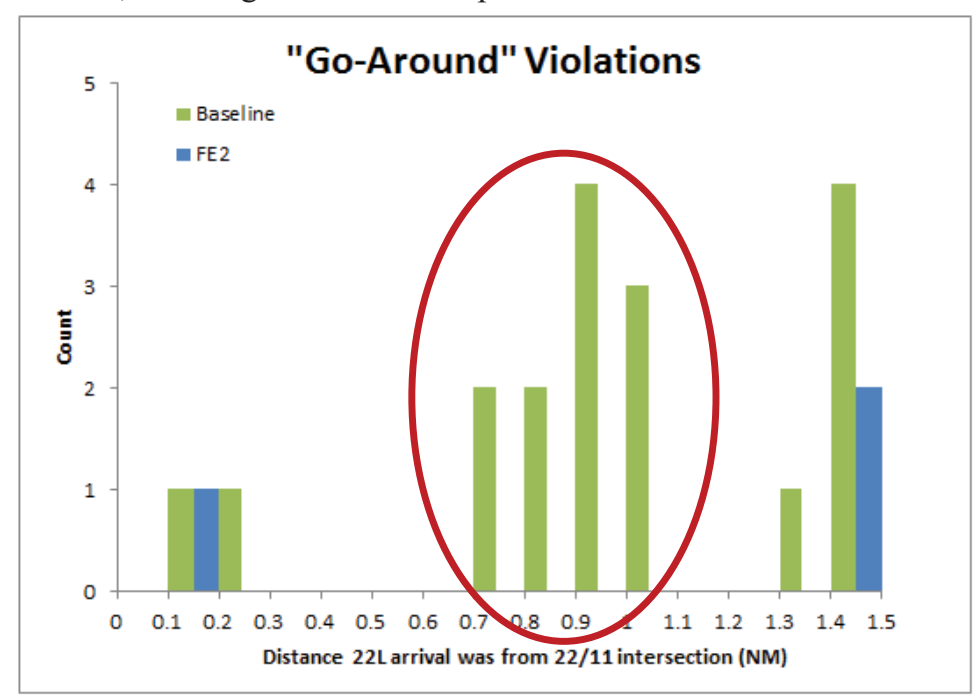

Figure 21: Go-Around Violations.
In terms of safety, the "go-around" violation data suggested that only the Futures condition could safely increase throughput. The go-around violations were logged whenever the arrivals on EWR11 and EWR22L were spaced too closely to each other during landing. A go-around violation was defined as occurring if the aircraft landing on EWR11 was at its threshold and the aircraft landing on EWR22L had not yet crossed the runway intersection and was less than 1.5 miles out. Figure 21 shows all of the go-around violations that occurred in the study. There were three go-around violation cases observed in the Futures condition, but they were borderline cases that, as identified during a follow-up discussion with a subjectmatter expert from EWR tower, in today's operations would not be considered a 
violation. Therefore, the go-around violations with safety implications occurred only in the Baseline condition (circled in Figure 21).

A follow-up benefit analysis was performed to evaluate the annualized benefit of the increased traffic once the realistic wind and traffic demand were taken into account. ${ }^{23}$ The analysis examined the meteorological conditions suitable for using the 11-22L landing runway configuration, and estimated the actual resulting potential for increasing arrival throughput. Aviation System Performance Metrics (ASPM) data were used to determine the traffic demand, runway configurations, meteorological conditions, and wind magnitudes/directions during 2007, 2009 and 2012. The annualized benefit analyses consisted of two parts: (1) identifying the availability of using runway 11 in addition to runway $22 \mathrm{~L}$ under favorable wind and meteorological conditions beyond the current level of its usage, and (2) applying the increased throughput identified by the simulation study to the 11-22L arrival configuration that can be used across an entire year.

Using fairly conservative assumptions about the meteorological conditions, runway usage, and peak demand characteristics, the analysis showed that the 11-22L runway configuration could have been used more than twice as often during high-demand periods (i.e., when arrival demand exceeded throughput), which in turn could have either reduced delays to the impacted aircraft by approximately 15 minutes per aircraft, or increased the overall throughput by approximately $8 \%-11 \%$ per year. This new operation has the potential to deliver even greater benefits if it were extended to include other runway configurations and demand conditions. The results suggest that a large throughput/delay benefit can be gained from a modest extension of the TMA-TM and make a significant impact in the New York area.

\section{Sharing of Airspace Resources (SOAR)}

The AOL's research group focused on Sharing of Airspace Resources (SOAR) is working to develop tools and procedures for conducting Metroplex operations with arriving and departing aircraft flows that share the same airspace. The concept of shared airspace in TRACONs allows more efficient routes by sharing a common airspace across different arrival and departure flows. Aircraft from one flow could use the same airspace as another flow, provided there are available gaps in the latter flow; this interaction of departure and arrival flow require timely coordination of traffic by controllers. Modeling studies have shown that the hybrid use of spatial and temporal spacing supports more efficient routes.

A first evaluation was conducted in the AOL in 2012

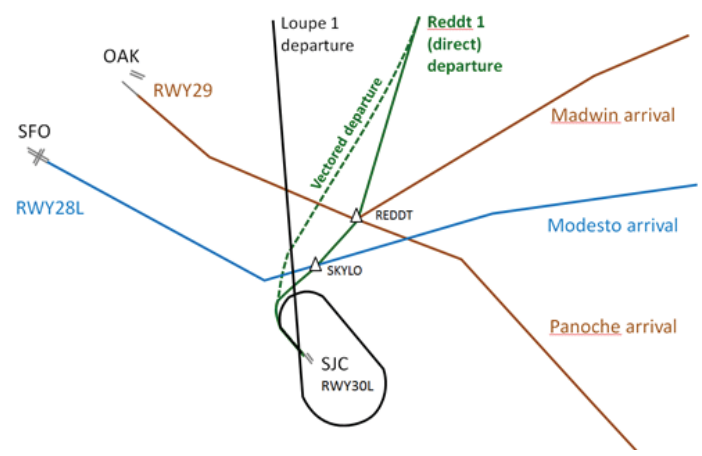

Figure 22: Arrival Departure problem addressed in SOAR 1 simulation in 2012.

using trajectory-based tools to coordinate departures leaving San Jose airport through gaps in the San Francisco and Oakland arrival stream (see Figure 22). The simulation assessed the efficiency and safety of 96 departures, during which the SJC tower had a tool to identify departures that could fly through predicted gaps in the arrival flow. Otherwise, a safe, but less efficient, route was used to keep the departures underneath the arrival flows. Additionally, the arrival controller was able to control the SJC departures right after take-off using a point-out coordination procedure. The simulation manipulated the accuracy of departure time (accurate vs. inaccurate) as well as which sector took control of the departures after take-off (departure vs. arrival sector) in a $2 \times 2$ full factorial design. Results show that coordination time decreased and climb efficiency increased when the arrival sector controlled the aircraft right after take-off. Also, climb efficiency increased when the departure times were more accurate. Coordination was shown to be a critical component of tactical operations in shared airspace. Although workload, coordination, and safety were judged by controllers as acceptable in the simulation, improved tools and coordination procedures seemed warranted ${ }^{24}$. 
Therefore, a second research phase situated in the New York airspace is currently underway. In this simulation, more emphasis is placed on developing tools and procedures for combining temporal and spatial information in the complex Metroplex environment. These tool prototypes have been developed and implemented in MACS and include Multi-Route and Route-Crossing tools and capabilities for departure release coordination. Figure 23 depicts the Multi-Route and Rout-Crossing tool
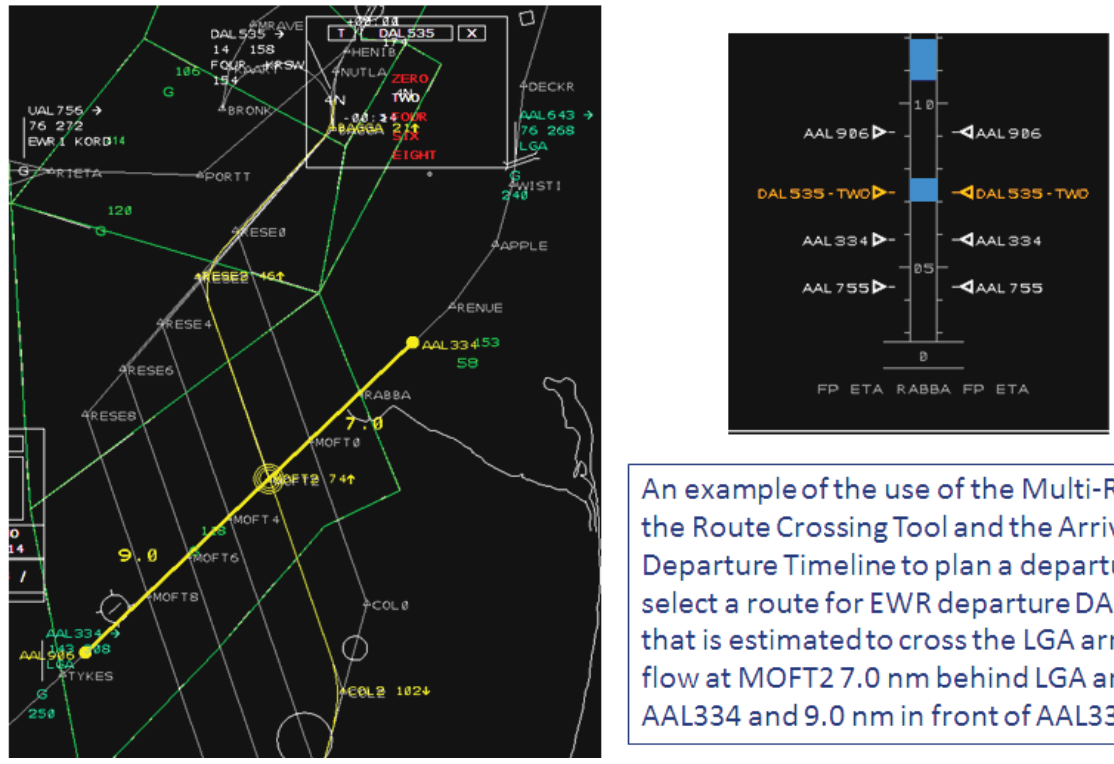

An example of the use of the Multi-Route, the Route Crossing Tool and the Arrival \& Departure Timeline to plan a departure and select a route for EWR departure DAL535 that is estimated to cross the LGA arrival flow at MOFT2 $7.0 \mathrm{~nm}$ behind LGA arrival AAL334 and $9.0 \mathrm{~nm}$ in front of AAL334.

Figure 23: Tools developed for the SOAR project.

prototypes in an environment in which EWR arrivals share airspace with La Guardia (LGA) arrivals.

\section{Increased System Autonomy}

TBO can be considered a main enabler of many NextGen and SESAR functions, and is also an important stepping stone towards a true transformation of the airspace system beyond NextGen. However, given the muchdocumented limitations of the current system, there also needs to be a fundamental paradigm shift in the allocation of functions between humans and automation to truly transform the airspace system towards increased mobility, safe and efficient growth in global operations, and enabling many of the new vehicles and operations that will be coming on-line over the next decades ${ }^{25}$. Moving beyond the human-operated manual air traffic management system that we have today will require highly capable systems that can conduct many operations autonomously as well as effective human/autonomy teaming strategies that ensure safe and efficient operations. NASA has conducted research on air traffic control operations under higher levels of automation and autonomy for over more than a decade. In close cooperation with other researchers at NASA Ames and Langley, the AOL integrated many concepts and algorithms into the envisioned air traffic operational environments and conducted a large body of fundamental human/systems integration research that has provided valuable insights into limitations and opportunities of different air traffic paradigms. The subsequent section summarizes some of this research. More detailed information is available in ${ }^{25,26,27,28}$.

\section{Air Traffic Control Operations under Higher Levels of Automation and Autonomy}

In 2008 the AOL started a series of studies focused on safely increasing capacity through new ways of human/automation collaboration for separation assurance. The studies were conducted with the over-arching goal of determining whether separation assurance automation can be integrated into air traffic control operations in an acceptable and safe manner. These studies investigated a range of issues including the proper levels of automation for given capacity targets, off-nominal operations from both air and ground perspectives, and sustained near-fullmission operations with many tasks allocated to the automation in the presence of convective weather and scheduling constraints.

Overall, it was found that, if properly integrated, advanced air traffic control automation has the potential to solve the envisioned airspace capacity problem. The automation was largely effective and robust, and an acceptable function allocation strategy between controllers and automation began to develop: allocating routine conflict avoidance to the automation, unusual situations to the controller, and providing information about short-term conflicts that gives the controller a large enough window of opportunity during which they can intervene with a solution. The studies started to identify the proper balance between the roles of humans and automation to maintain a consistent and appropriate level of engagement for the controllers. Controllers were comfortable with the automation dealing with several routine tasks without their involvement, but wanted decision-making authority and 
support in maintaining an overall awareness. The three studies have also served to shed light on specific tasks where the allocation of function was less clear, such as handling short-term problems. Feedback and results also showed that further technological development is necessary to improve trajectory prediction and conflict detection accuracy. The need for further procedural development to govern controller/automation teaming and air/ground interactions was also highlighted ${ }^{25}$.

Following up on the earlier findings a 2012 human-in-the-loop air traffic control simulation investigated a gradual paradigm-shift in the allocation of functions between operators and automation. Air traffic controllers staffed five adjacent high-altitude en route sectors and, during the course of a two-week experiment, worked traffic under different function-allocation approaches aligned with four increasingly mature NextGen operational environments (see Figure 24). The traffic was primarily ground-managed with a small percentage of aircraft conducting airborne self-separation operations. The four NextGen 'time-frames' ranged from near current-day operations to nearly fully-automated control in which the ground system's automation was responsible for detecting conflicts, issuing strategic and tactical resolutions, and alerting the controller to exceptional circumstances. The study provided a unique opportunity to investigate transitional stages.
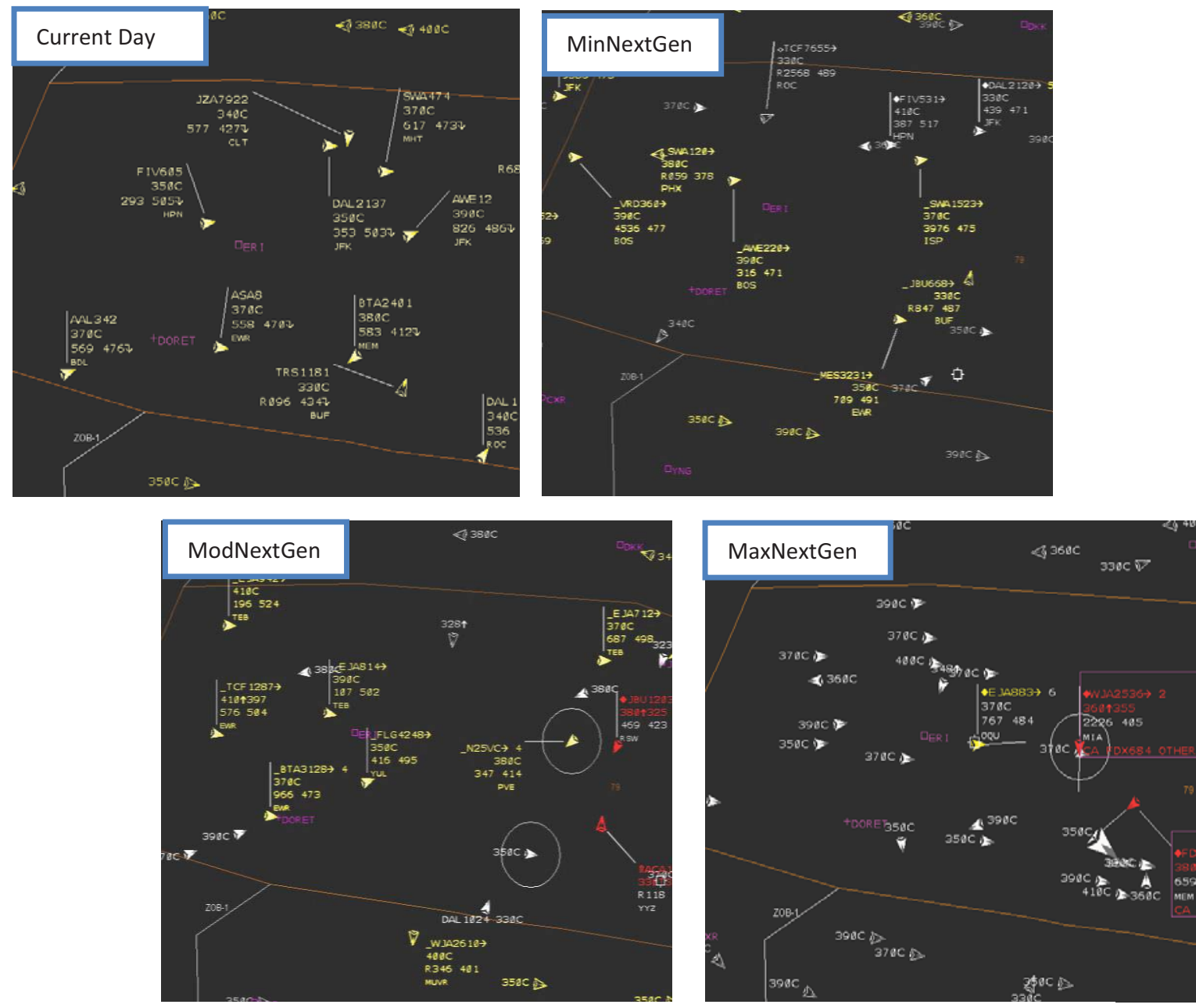

Figure 24: Excerpts from the controller displays for the 4 stages used in the 2012 study

The first stage, "Current Day", was designed to provide data approximating current day operations with the addition of ADS-B out surveillance data. The traffic levels were selected to be representative of current day peak traffic levels with a Monitor Alert Parameter (MAP) value of 18 aircraft per sector.

The second stage, labeled "Minimum NextGen", introduced limited data communication between the groundside and $25 \%$ of the simulated aircraft. This data communication enabled an automatic transfer of communication of aircraft from one sector to the next. This eased the controller workload in handling those aircraft. It was expected that controllers could potentially ignore self-separating aircraft, because they had no routine duties with regard to 
them. This stage also introduced more decision support capabilities for the controllers, none of which were integrated with data comm. So, all control instructions still had to be communicated via voice. It was hoped that the new technologies could enable a capacity increase of $20 \%$, and the MAP value was set to 22 aircraft per sector for the "Minimum NextGen".

In the third stage, entitled "Moderate NextGen", the controller planning tools and the flight management systems on-board the aircraft were integrated with data comm., and $50 \%$ of the aircraft were assumed data comm. equipped. Controllers were able to issue trajectory change instructions to equipped aircraft via data comm. Based upon earlier research, it was hypothesized that this environment could enable a capacity increase of $50 \%$ over the Baseline and therefore the MAP value was set to 27 for this stage.

In the final NextGen stage, referred to as "Maximum NextGen", the automation provided separation assurance autonomously and all aircraft were data comm. equipped. When conflicts were detected, automation computed trajectory-based resolutions and issued those directly to the flight deck, as long as the computed resolutions did not violate preset tolerances. Otherwise, the conflict was flagged to the controller for resolution. Prior research had indicated the scalability of this approach, and therefore the traffic levels were selected at $100 \%$ over the Baseline with a MAP value of 36 aircraft per sector.
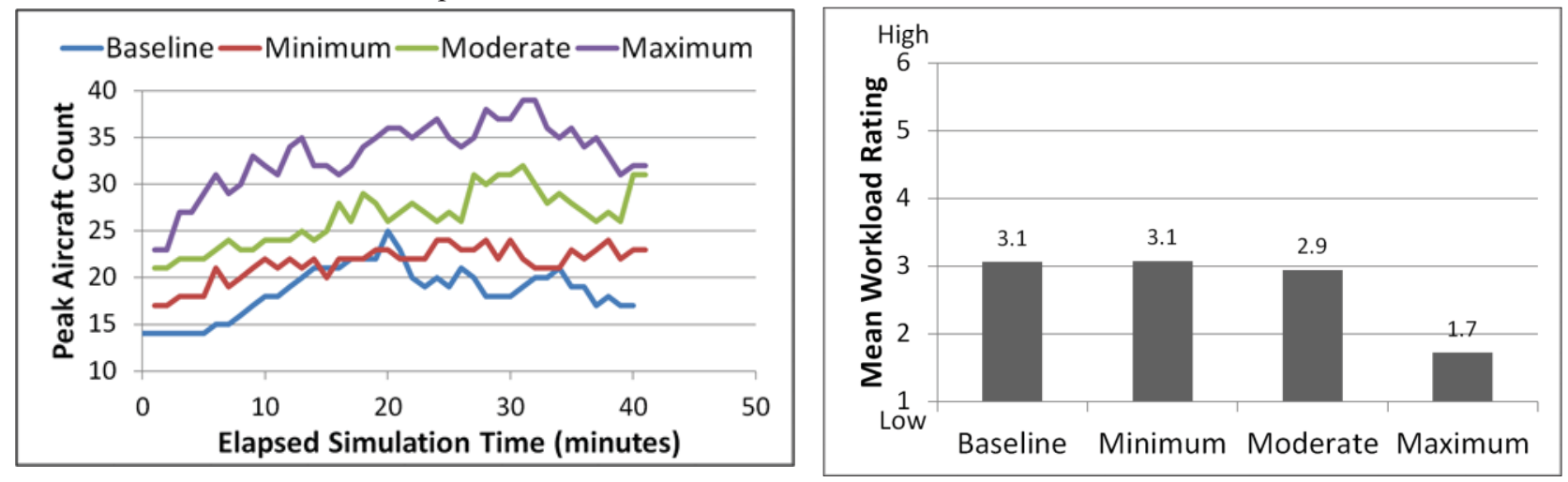

Figure 25: Peak aircraft count and workload rating for

Figure 25 contrasts the measured aircraft count to subjective controller workload ratings and shows that the aircraft count increased from the Baseline to the Minimum, the Moderate and the Maximum condition, whereas the workload stayed constant for Baseline, Minimum and Moderate conditions. Only the Maximum condition showed a significantly lower workload. The maximum highly automated condition outperformed the others also the other metrics, such as flight path efficiency while not compromising safety over the baseline. ${ }^{26,27.28}$.

Somewhat unexpectedly it was also found that the maximum condition achieved the highest situation awareness and acceptability ratings (as shown in Figure 26).
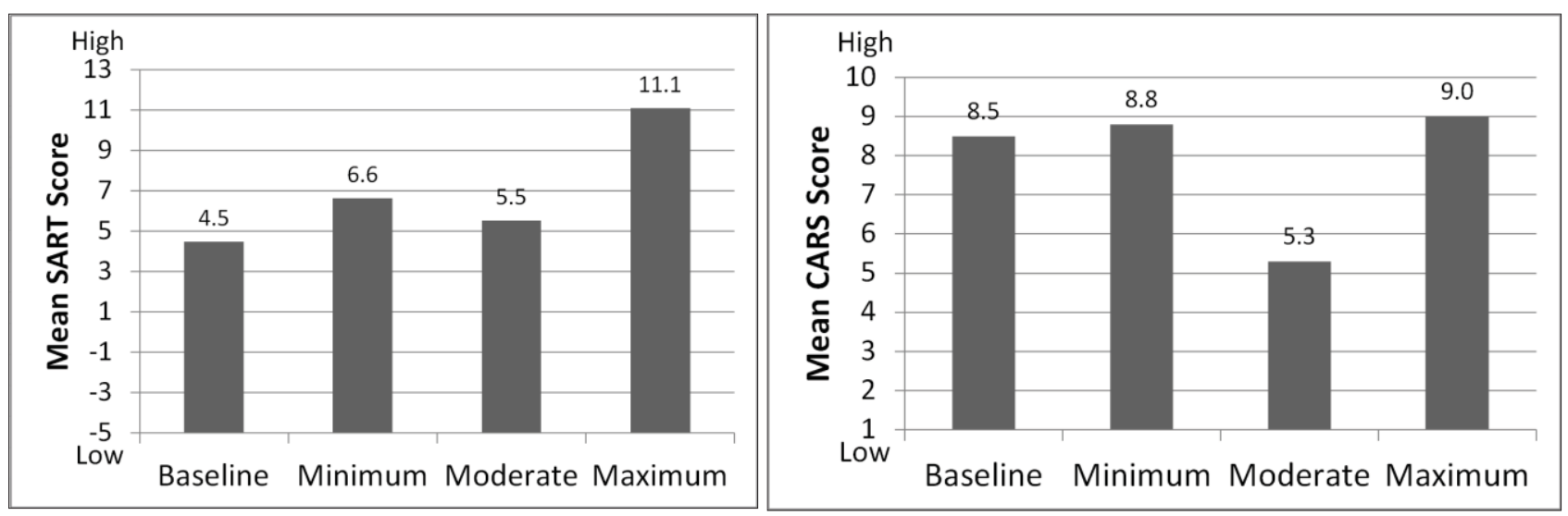

Figure 26: Situation awareness and acceptability ratings

Conversely, the moderate condition was the most problematic, exhibiting more separation violations than the others (not shown here) and the lowest acceptability ratings. This indicates that simply adding automated functions without changing the operational paradigm may be problematic. The results provide much support for pursuing

18

American Institute of Aeronautics and Astronautics 
concepts of increased autonomy and developing human/autonomy teaming strategies that can effectively utilize the considerable benefits of advanced air traffic control automation.

\section{Conclusion}

The Airspace Operations Laboratory at NASA Ames Research Center has developed powerful capabilities for efficiently conducting research on the future air transportation system. Several additional NASA technologies have been integrated with the AOLs primary simulation capabilities where appropriate to conduct system level evaluations of near-term technologies that are being transitioned to the field. The AOL's rapid prototyping and flexible simulation capabilities have proven a highly effective environment to progress the initiation of trajectorybased operations and support the mid-term implementation on NextGen. Fundamental questions about accuracy requirements are addressed as well as real world problem on how to improve operations in some of the most complex airspaces in the US. Looking beyond NextGen, the AOL has started exploring hybrid human/automation control strategies and largely autonomous operations in the air traffic control domain. Initial results indicate largely improved capacity, low operator workload, good situation awareness and acceptability for controllers teaming with autonomous air traffic systems. While much research and development needs to be conducted to make such concepts a reality, these approaches have the potential to truly transform the airspace system towards increased mobility, safe and efficient growth in global operations and enabling many of the new vehicles and operations that are expected over the next decades.

\section{Acknowledgements}

The author list of this paper represents only a small subset of all the people who are critical to developing the technologies and conducting the research in the AOL. We greatly appreciate all the hard work of the entire AOL staff and all the folks in the human/systems integration division at NASA Ames Research Center that support our work. Moreover much of the capabilities and research described here is a result of our close collaboration with many colleagues in the Aviation Systems Division at NASA Ames and researchers and developers at NASA Langley Research Center. We greatly appreciate everybody's support and are pleased that the integrated NASA simulation technologies are used in many places across the agency and by our partners. This research was sponsored by the Concepts and Technology Development project and the Systems Analysis, Integration, and Evaluation Project of NASA's Airspace Systems Program.

\section{References}

${ }^{1}$ Prevot T, Smith N, Palmer E, Mercer J, Lee P, Homola J, and Callantine T. (2006) The Airspace Operations Laboratory (AOL) at NASA Ames Research Center, AIAA Modeling and Simulation Technologies Conference AIAA-2006-6112, AIAA, Reston, VA, 2006.

${ }^{2}$ Prevot, T., P. Lee, T. Callantine, J. Mercer, J. Homola, N. Smith, et. al. (2010). Human-In-The-Loop Simulation of NextGen Concepts in the Airspace Operations Laboratory. Proceedings of the AIAA Modeling and Simulation Technologies Conference, Toronto, Canada.

${ }^{3}$ NASA (2014) NASA Aeronautics Research Mission Directorate website. URL: www.aeronautics.nasa.gov retrieved on May 21, 2014

${ }^{4}$ Prevot T. (2002) Exploring the Many Perspectives of Distributed Air Traffic Management: The Multi-Aircraft Control System MACS. In S. Chatty, J. Hansman, \& G. Boy. (Eds). HCI-Aero 2002, AIAA Press, Menlo Park, CA. pp 149-154, 2002.

${ }^{5}$ H. Swenson, T. Hoang, S. Engelland, D. Vincent, T. Sanders, B. Sanford, et al., "Design and operational evaluation of the Traffic Management Advisor at the Fort Worth Air Route Traffic Control Center," Proceedings of the 1st USA/Europe Air Traffic Management Research and Development Seminar, Saclay, France, July 1997.

${ }^{6} \mathrm{FAA}(2014)$ Terminal Automation Modernization and Replacement (TAMR) http://www.faa.gov/air traffic/technology/tamr/ retrieved 5/14/2014

${ }^{7} \mathrm{FAA}(2014)$ En Route Automation Modernization (ERAM) http://www.faa.gov/air_traffic/technologyeramr/ retrieved 5/14/2014

${ }^{8}$ Palmer M and Ballin G. A High-Performance Simulated On-Board Avionics Architecture to Support Traffic Operations

Research. AIAA Modeling and Simulation Technologies Conference, AIAA-2003-5452. Austin, TX, 2003

${ }^{9}$ Prevot T., C. L. Brasil, \& M. J. Mainini (2010) Multi-Sector Planning Tools for Trajectory-based Operations, 10th AIAA-2010-9275 AIAA Aviation Technology, Integration, and Operations Conference, Dallas Fort-Worth, TX 
${ }^{10}$ Smith N.M., P. U. Lee, T. . Prevot, A. M. Kessell, \& J. R. Homola (2010) A Human-in-the-Loop Investigation of Multi-Sector Planning Operations in the NextGen Mid-Term Timeframe, 10th AIAA Aviation Technology, Integration, and Operations Conference, Dallas Fort-Worth, TX

${ }^{11}$ Smith N.M. , B. K. Parke, P. U. Lee, C. D. Cabrall, E. . Chevalley, J. R. Homola, \& S. E. Morey (2013) NextGen Operations in a Simulated NY Area Airspace, 32nd Digital Avionics Systems Conference, Syracuse, NY

${ }^{12}$ Benefits and Feasibility of the Flexible Airspace Management Concept: A Human-in-the-loop Evaluation of Roles, Procedures, and Tools, Ninth USA/Europe Air Traffic Management Research and Development Seminar, ATM2011 (Paper 132), EUROCONTROL/FAA. Berlin, Germany, June 2011

${ }^{13}$ Lee P.U., R. . Mogford, W. W. Bridges, N. J. Buckley, M. . Evans, V. . Gujral, H. . Lee, D. N. Peknik, \& B. . Preston (2013) An Evaluation of Operational Airspace Sectorization Integrated System (OASIS) Advisory Tool, Proceedings of the AIAA Aviation 2013 Conference, Los Angeles, CA

${ }^{14}$ Erzberger H. Transforming the NAS: The Next Generation Air Traffic Control System, 24th International Congress of the Aeronautical Sciences, Yokohama, Japan, 2005.

${ }^{15}$ Erzberger, H. \& Heere, K. (2008) Algorithm and operational concept for solving short range conflicts. International Congress of the Aeronautical Sciences 2008-8.7.5, Anchorage, Alaska,

${ }^{16}$ Prevot, T., Baxley, B., Callantine, T., Johnson, W., Quon, L., Robinson, J., and Swenson, H., "NASA's ATM Technology Demonstration-1: Transitioning fuel efficient, high throughput arrival operations from simulation to reality," in Proceedings of the International Conference on Human-Computer Interaction in Aerospace (HCI-Aero 2012), Brussels, September 2012.

${ }^{17}$ Baxley, B., Johnson, W., Swenson, H., Robinson, J., Prevot, T., Callantine, T., Scardina, J., and Greene, M., Air Traffic Management Technology Demonstration-1 concept of operations (ATD-1 ConOps v2.0). NASA Technical Memorandum 2013-218040. Hampton, VA: NASA Langley Research Center, September 2013.

${ }^{18}$ Callantine T., Hunt, S. and Prevot, T. (2014) Simulation Evaluation of Controller-Managed Spacing Tools under Realistic Operational Conditions. in Proceedings of the International Conference on HumanComputer Interaction in Aerospace (HCI-Aero 2014), Santa Clara, CA, July 2014

${ }^{19}$ Callantine, T., Cabrall, C., Kupfer, M., Martin, L., Mercer, J. and Prevot, T, (2014) System-Level Performance Evaluation of ATD-1 Ground-Based Technologies, 14th AIAA Aviation Technology, Integration, and Operations (ATIO) Conference, Atlanta, GA, July

${ }^{20}$ Federal Aviation Administration. "NextGen Implementation Plan 2013." FAA, Washington, D.C., 2013.

${ }^{21}$ SESAR Joint Undertaking (2014) http://www.sesarju.eu/ retrieved May 20, 2014

${ }^{22}$ Mercer, J., Bienert, N Gomez, A. Hunt S, Green S., Prevôt, T. and Wu M.G.. "The Impact of Trajectory Prediction Uncertainty on Air Traffic Controller Performance and Acceptability" AIAA Aviation Conference, AIAA, Reston, VA, 2013.

${ }^{23}$ Lee, P.U. Idris Husni M and Smith N.M. Annualizing Throughput Benefits at Newark Airport using a New Approach to Converging Runway Operations, 14th AIAA Aviation Technology, Integration, and Operations (ATIO) Conference, Atlanta, GA, July

${ }^{24}$ E. . Chevalley, B. K. Parke, P. U. Lee, F. G. Omar, H. . Lee, N. . Bienert, J. M. Kraut, \& E. A. Palmer (2013) Scheduling and separating Departures crossing arrival flows in shared airspace, Proceedings of the 32nd the Digital Avionics Systems Conference, Syracuse, NY

${ }^{25}$ Prevôt, T., Homola, J., Martin, L., Mercer, J. and Cabrall, C. Toward Automated Air Traffic Control Investigating a Fundamental Paradigm Shift in Human/System Interaction. International Journal of HumanComputer Interaction, 28 (2), 77-98, 2012.

${ }^{26}$ Wing, D., Prevôt, T., Lewis, T., Martin, L., Johnson, S., Cabrall, C., et al. Pilot and Controller Evaluations of Separation Function Allocation in Air Traffic Management. Proceedings of the USA/Europe Air Traffic Management R\&D Seminar, Chicago, IL., 2013.

${ }^{27}$ Homola, J, Martin, L, Mercer, J. and Prevot T,. Exploring Workload Factors Across Future Environments Proceedings of the International Conference on Human-Computer Interaction in Aerospace (HCI-Aero 2014), Santa Clara, CA, July 2014

${ }^{28}$ Mercer, J., Homola, J, Cabrall, C., Martin, L., Morey S., Gomez, A., and Prevot, T. Human-Automation Cooperation for Separation Assurance in Future NextGen Environments Proceedings of the International Conference on Human-Computer Interaction in Aerospace (HCI-Aero 2014), Santa Clara, CA, July 2014 